\title{
Negative regulation of Gen4 and Msn2 transcription factors by Srb10 cyclin-dependent kinase
}

\author{
Yong Chi, ${ }_{1}^{1}$ Michael J. Huddleston, ${ }^{3}$ Xiaolong Zhang, ${ }^{3}$ Richard A. Young, ${ }^{4}$ Roland S. Annan, ${ }^{3}$ \\ Steven A. Carr, ${ }^{3}$ and Raymond J. Deshaies ${ }^{1,2,5}$ \\ ${ }^{1}$ Division of Biology and ${ }^{2}$ Howard Hughes Medical Institute, California Institute of Technology, Pasadena, California 91125, \\ USA; ${ }^{3}$ Research Mass Spectrometry Laboratory, SmithKline Beecham Pharmaceuticals, King of Prussia, Pennsylvania 19406, \\ USA; ${ }^{4}$ Whitehead Institute for Biomedical Research and Department of Biology, Massachusetts Institute of Technology, \\ Cambridge, Massachusetts 02142, USA
}

The budding yeast transcriptional activator Gen4 is rapidly degraded in an SCF ${ }^{\mathrm{Cdc}}$-dependent manner in vivo. Upon fractionation of yeast extracts to identify factors that mediate Gen4 ubiquitination, we found that Srb10 phosphorylates Gen4 and thereby marks it for recognition by SCF ${ }^{\mathrm{Cdc} 4}$ ubiquitin ligase. Srb10 is a physiological regulator of Gen4 stability because both phosphorylation and turnover of Gen4 are diminished in srb10

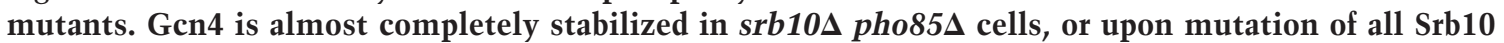
phosphorylation sites within Gcn4, suggesting that the Pho85 and Srb10 cyclin-dependent kinases (CDKs) conspire to limit the accumulation of Gen4. The multistress response transcriptional regulator Msn2 is also a substrate for Srb10 and is hyperphosphorylated in an Srb10-dependent manner upon heat-stress-induced translocation into the nucleus. Whereas Msn2 is cytoplasmic in resting wild-type cells, its nuclear exclusion is partially compromised in srb10 mutant cells. Srb10 has been shown to repress a subset of genes in vivo, and has been proposed to inhibit transcription via phosphorylation of the C-terminal domain of RNA polymerase II. We propose that Srb10 also inhibits gene expression by promoting the rapid degradation or nuclear export of specific transcription factors. Simultaneous down-regulation of both transcriptional regulatory proteins and RNA polymerase may enhance the potency and specificity of transcriptional inhibition by Srb10.

[Key Words: Kin28; Msn5; mediator; SCF; phosphopeptide; mass spectrometry]

Received November 20, 2000; revised version accepted March 2, 2001.

Precise modulation of intracellular protein concentration is an important means by which diverse cellular processes are regulated. One way cells effectively achieve this is through proteolysis of key regulatory proteins. The ubiquitin system is the major cytoplasmic pathway by which proteins are degraded. Ubiquitin-mediated degradation of cellular proteins involves attachment of ubiquitin chains to substrate proteins, which are subsequently targeted for degradation by the $26 \mathrm{~S}$ proteasome (Ciechanover et al. 2000). Assembly of a multiubiquitin chain upon a substrate typically requires three classes of enzymes: the ubiquitin-activating enzyme (E1), a ubiquitin-conjugating enzyme (E2), and a ubiquitin ligase (E3). The E1 enzyme activates ubiquitin in an ATP-dependent manner by linking to its $\mathrm{C}$ terminus via a thioester bond. The E2 enzyme accepts the thioesterified ubiquitin and transfers it to a lysine resi-

${ }^{5}$ Corresponding author.

E-MAIL deshaies@its.caltech.edu; FAX (626) 449-0756.

Article and publication are at www.genesdev.org/cgi/doi/10.1101/ gad.867501. due of the target protein. This step usually requires assistance from an E3 enzyme. There are potentially 13 E2-like proteins in budding yeast. In contrast, there are two distinct classes of E3s: the HECT domain family and the RING domain family (Deshaies 1999; Seol et al. 1999; Jackson et al. 2000). The RING domain family of E3s includes multimeric complexes such as SCF and anaphase-promoting complex/cyclosome (APC/C), as well as single subunit ligases like Ubr1. Whereas HECT E3s act as a direct intermediary by accepting ubiquitin from E2 and transferring it to substrate, RING-based E3s are thought to catalyze ubiquitination by enabling the direct transfer of ubiquitin from E2 to substrate (Seol et al. 1999). Regardless of their mechanism of action, E3s typically bind directly to E2 and to substrate, suggesting that they provide substrate specificity in cellular ubiquitination reactions.

One salient example of how proteolysis can provide a regulatory switch stemmed from genetic analysis of the $\mathrm{G}_{1} / \mathrm{S}$ transition in budding yeast (Schwob et al. 1994). Cells harboring temperature-sensitive mutations in SKP1, CDC53, and CDC4 arrest in $\mathrm{G}_{1}$ phase at the nonpermissive temperature because they fail to degrade 
the S-phase cyclin/cyclin-dependent kinase (CDK) inhibitor Sic1 (Schwob et al. 1994; Bai et al. 1996). Subsequent in vitro reconstitution of Sicl ubiquitination led to the identification of $\mathrm{SCF}^{\mathrm{Cdc} 4}$, the prototype of the SCF (for Skp, Cdc53/cullin, F-box receptor) family of ubiquitin ligases (Feldman et al. 1997; Skowyra et al. 1997; Verma et al. 1997c). Recently, Hrt1 (also known as Roc1 and Rbx1), an essential fourth subunit of the SCF complex, was identified (for review, see Deshaies 1999). The SCF family of ubiquitin ligases is potentially large given that the yeast genome encodes at least 17 potential F-box receptor subunits (Patton et al. 1998b), and at least two other SCF complexes-SCF ${ }^{\mathrm{Grr} 1}$ and $\mathrm{SCF}^{\mathrm{Met} 30}$-have been identified in budding yeast (Patton et al. 1998a). Cdc34 appears to be the primary E2 enzyme that interacts with SCF complexes and catalyzes ubiquitination of their substrates in budding yeast.

Besides Sic1, the CDK inhibitor Far1 (Henchoz et al. 1997) and the replication initiation protein Cdc6 (Drury et al. 1997; Elsasser et al. 1999) have been shown to be substrates of $\mathrm{SCF}^{\mathrm{Cdc} 4}$. A common feature in the ubiquitination of $\mathrm{SCF}^{\mathrm{Cdc} 4}$ substrates is that they must be phosphorylated by the major cell cycle CDK, Cdc28 (Henchoz et al. 1997; Verma et al. 1997c; Elsasser et al. 1999). Phosphorylation appears to serve as a general signal that promotes binding of the F-box receptor Cdc4 to the substrates (Feldman et al. 1997; Skowyra et al. 1997). To investigate the generality of the Cdc34/SCF ${ }^{\mathrm{Cdc} 4}$ pathway, we initiated biochemical analysis of the roles of these proteins in Gcn4 ubiquitination. Gcn4, a transcription activator involved in the regulation of amino acid and purine biosynthetic genes (Hinnebusch 1992), is very unstable, and its degradation is dependent on Cdc34 and proteasome function (Kornitzer et al. 1994). Very recently, it was shown that Gen4 is stabilized in $c d c 4$, $c d c 53$, and skp1 temperature-sensitive mutants, and in pho85 cells (Meimoun et al. 2000). This suggests that $\mathrm{SCF}^{\mathrm{Cdc} 4}$ contributes to the rapid degradation of Gen4 in vivo and that a CDK other than Cdc28 is involved in Gen4 degradation. However, there is no biochemical evidence to date that either $\mathrm{SCF}^{\mathrm{Cdc} 4}$ or Pho85 directly promotes ubiquitination of Gen4.

Here we provide evidence that the Srb10 CDK of the SRB/mediator complex phosphorylates both Gen4 and the multistress response transcription factor Msn2. Whereas Srb10 targets Gcn4 for $\mathrm{SCF}^{\mathrm{Cdc} 4}$-dependent degradation, it helps enforce the nuclear exclusion of Msn2. It has been proposed that Srb10 negatively regulates transcription of certain genes by binding and phosphorylation of the C-terminal domain (CTD) of the largest subunit of RNA polymerase II (Hengartner et al. 1998). Our results suggest that Srb10 can also repress the transcription of specific genes by directly antagonizing transcriptional activators.

\section{Results}

\section{Ubiquitination of Gcn4 in yeast extracts}

Ourin vitro studies on Gen4 ubiquitination were prompted by the observation that Gcn 4 turnover in vivo depends on Cdc34 (Kornitzer et al. 1994). As a first step toward understanding the mechanism and regulation of Gen4 turnover, we set out to reconstitute Gcn4 ubiquitination in vitro. Ubiquitination of $\left[{ }^{35} \mathrm{~S}\right]$ methionine-labeled Gen 4 was evaluated in $\mathrm{G}_{1}$-cyclin-depleted whole-cell yeast extracts as described for Sic1 (Verma et al. 1997c). Although ubiquitination of Sicl required the addition of GST-Cln2 to supply Cdc28 kinase activity (Fig. 1A, lanes 6,7), ubiquitination of Gen4 did not (lanes 2,3). Multiubiquitination of both substrates was confirmed by the addition of methyl-ubiquitin (lanes 4,8), a chain-terminating derivative of ubiquitin. Concomitantly with ubiquitination, Gcn 4 exhibited a characteristic molecular weight up-shift upon incubation in yeast extract (cf. Fig. 1A, lanes 1,2). To test if this modification was caused by phosphorylation, we first incubated $\mathrm{Gcn} 4^{\mathrm{HA}}$ with a yeast extract fraction enriched for this activity, and then immunoprecipitated $\mathrm{Gcn} 4^{\mathrm{HA}}$ and treated it with calf intestinal alkaline phosphatase (CIAP). As shown in Figure 1B, CIAP treatment reversed the molecular weight shift of Gcn4, indicating that it arises from phosphorylation.

The results above suggested that Gen 4 might be targeted for ubiquitination by a novel pathway. Alternatively, a protein kinase besides Cde28 may be able to direct Gcn 4 to the SCF pathway. To distinguish between these possibilities, we fractionated whole cell extract from mutant $c d c 4^{t s}$ cells into a protein kinase fraction and an SCF-containing fraction (the SCF fraction lacks the E2 Cdc34; Verma et al. 1997c). As shown in Figure 1C, multiubiquitination of Gen4 occurred only when both yeast fractions and exogenous Cdc 34 and Cdc4 were added. Since ubiquitination of Sic1 did not require the kinase fraction (data not shown), we concluded that Gcn 4 must be phosphorylated by an unknown protein kinase before it can be ubiquitinated by the $\mathrm{SCF}^{\mathrm{Cdc} 4} /$ Cdc34 pathway.

Identification of the Srb10 subunit of RNA polymerase II holoenzyme as a Gcn4 kinase

To identify the activity required for Gen 4 ubiquitination in vitro, we first attempted to purify this activity by conventional column chromatography. We used both Gen4 kinase assays and ubiquitination assays to monitor this activity during purification. Unfortunately, we did not purify enough activator to obtain protein sequence. However, upon partial purification (Fig. 2A), we identified a high-molecular-weight Gcn4 kinase activity that cofractionated with the ubiquitination-promoting activity (Fig. 2B). Note that although there are two contaminating low-molecular-weight Gcn4 kinases that peak in fractions 11 and 15, neither of these fractions can sustain ubiquitination of Gcn4 by SCF ${ }^{\mathrm{Cdc} 4}$. We suspected the kinase activity was a CDK because the Cdc28 CDK is required for $\mathrm{SCF}^{\mathrm{Cdc} 4}$-dependent ubiquitination of Sicl, Far1, and Cdc6. Given that Kin28 and Srb10, both of which are components of the RNA polymerase II holoenzyme (Myer and Young 1998), are the only CDKs 
Figure 1. Gcn4 ubiquitination in yeast extracts requires SCF components and a protein kinase activity other than $\mathrm{Cdc} 28$. $(A)\left[{ }^{35} \mathrm{~S}\right] \mathrm{Me}$ thionine-labeled Gcn4 (lanes 1-4) or Sic1 (lanes 5-8) synthesized by in vitro translation were incubated with $\mathrm{G}_{1}$-cyclin-depleted yeast whole cell extracts from RJD885 strain in the absence (lanes 2, 6) or the presence (lanes 3, 7) of purified GST-Cln2. Uba1, Cdc34, and SCF activities were supplied by the yeast extracts. Lanes 1 and 5 contained only input substrates. Methylated ubiquitin (me-ubiquitin) was used instead of wild-type ubiquitin in lanes 4 and 8 . Encircled $\mathrm{P}$ refers to phosphorylated forms of Sicl and Gen4. All samples in panels $A-C$ were evaluated by SDS-PAGE followed by autoradiography. (B) $\left[{ }^{35} \mathrm{~S}\right]$ Methionine-labeled Gen $4{ }^{\mathrm{HA}}$ translation product was phosphorylated by the DEAE flow-through fraction of RJD885 whole cell extract (see Materials and Methods). An aliquot of the reaction was immunoprecipitated using 12CA5 antibody and mock-treated (lane 2) or treated with calf intestinal alkaline phosphatase (CIAP) in the absence (lane 3) or the presence (lane 4) of phosphate inhibitor as described (Verma et al. 1997c). Immunoprecipitated input Gen $4^{\mathrm{HA}}$ is shown in lane 1. (C) Ubiquitination of Gcn4 in fractionated yeast extracts from a $c d c 4^{t s}$ strain (RJD893). Extract fractions lacking Cdc34 but supplying either SCF components or a kinase activity were used (see Materials and Methods). A complete reaction (lane 6) included a kinase fraction $(\sim 10 \mu \mathrm{g})$, a ubiquitination fraction $(\sim 15 \mu \mathrm{g}), \mathrm{Cdc} 34$ (100 ng), and insect cell lysate containing baculovirus-expressed Cdc4 ( $4 \mu \mathrm{g}$ total protein; Verma et al. 1997c). In lanes 1-5, one or more of the above components was omitted, as indicated. Insect cell lysate containing baculovirus-expressed Cdc28 was used as a specificity control (lane 7) for the Cdc4 lysate.

known to reside in a high-molecular-weight complex, we tested whether either of these kinases was responsible for the purified activity. Extract fractions enriched for the high-molecular-weight Gcn4 kinase activity were prepared from SRB10 and $\operatorname{srb} 10 \Delta$ cells and tested for their ability to support Gen 4 ubiquitination by Cdc34 and purified recombinant $\mathrm{SCF}^{\mathrm{Cdc} 4}$ complex. As shown in Figure 2C, the kinase fraction from SRB10 but not from $s r b 10 \Delta$ cells supported Gcn 4 ubiquitination. In contrast, we did not observe any defect when the kinase fraction was prepared from a kin28 ${ }^{t s}$ strain (data not shown). Taken together, these observations suggest that Gen 4 is directly ubiquitinated by $\mathrm{Cdc} 34 / \mathrm{SCF}^{\mathrm{Cdc} 4}$, and that the Srb10 subunit of RNA polymerase II holoenzyme is the predominant protein kinase in yeast extract that is able to specify ubiquitination of Gen4 by this pathway.

\section{Srb10, but not Kin28, phosphorylates Gcn4 in vitro and targets it for SCF-dependent ubiquitination}

Because both Srb10 and Kin28 associate with the RNA polymerase II holoenzyme complex (Myer and Young 1998), we next tested whether either Srb10 or Kin28 could directly phosphorylate Gen 4 by immunoprecipi-
A

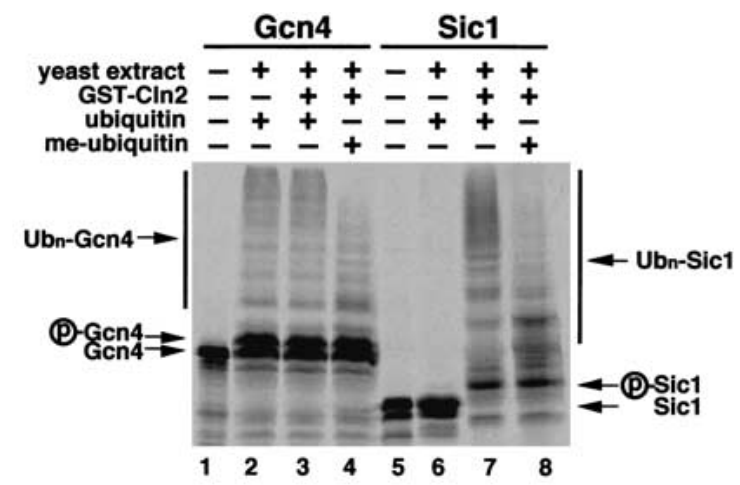

B

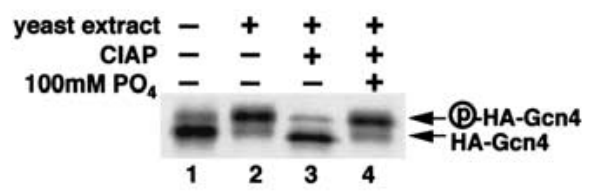

C

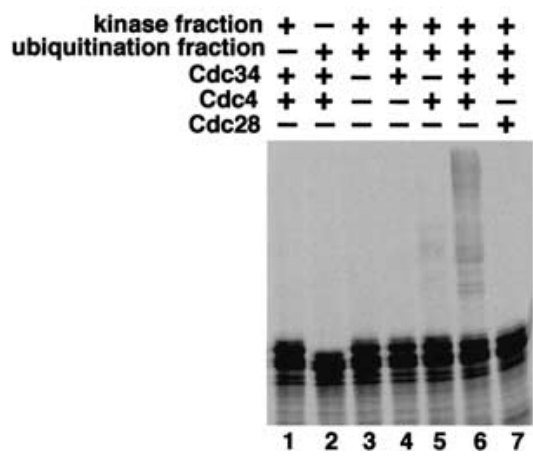

tating each of the kinases from yeast whole-cell extracts and performing kinase assays using purified Gen 4 expressed in Escherichia coli. Anti-myc immunoprecipitates from $S R B 10^{\text {myc9 }}$ cells exhibited potent Gen 4 kinase activity, whereas those from KIN28 ${ }^{\text {myc9 }}$ cells had little or no activity (Fig. 3A, lanes 2-4). As expected (Hengartner et al. 1998), GST-CTD (C-terminal domain) was phosphorylated by both Srb $10^{\text {myc9 }}$ and Kin $28^{\text {myc9 }}$ immunoprecipitates (lanes 6-8). GST-CTD kinase activity observed in the Kin $28^{\mathrm{myc} 9}$ immunoprecipitate was not caused by contaminating Srb10 because similar activity was recovered from an srb10 10 strain (lane 8). These data demonstrate that the high-molecular-weight Gcn4 kinase activity that we enriched for is owing to Srb10, not to Kin28. To further confirm the specificity of the kinase activity present in $\mathrm{Srb} 10^{\mathrm{myc} 9}$ immunoprecipitates, we evaluated the Gcn4 kinase activity of immunoprecipitates prepared from an $s r b 10-3^{m y c 9}$ strain, which harbors an active-site mutant form of the Srb10 kinase that is incorporated into the RNA polymerase II holoenzyme (Liao et al. 1995). Although similar amounts of Srb protein were present in $\mathrm{Srb} 10^{\mathrm{myc} 9}$ and Srb10-3 $3^{\mathrm{myc} 9}$ immunoprecipitates (Fig. 3B, lower panel), only the former phosphorylated Gen4 (Fig. 3B, upper panel). 
A

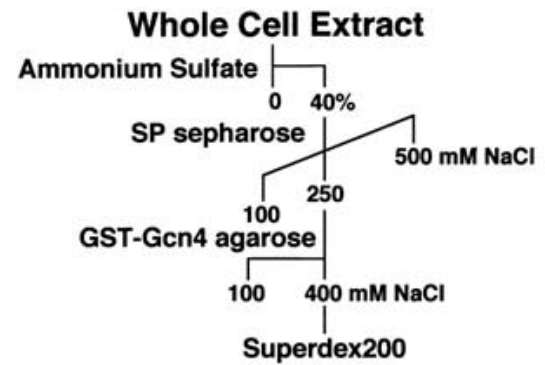

B

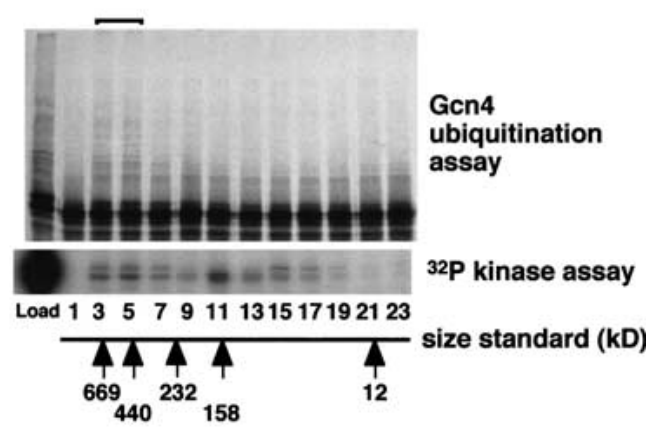

C

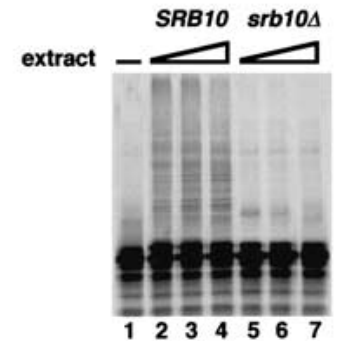

Figure 2. Identification of Srb10 as the protein kinase that promotes Gcn 4 ubiquitination in yeast extracts. (A) Purification scheme (see Materials and Methods for details). (B) The indicated fractions from a Superdex 200 column were evaluated for both protein kinase activity using Gcn 4 expressed in E. coli (bottom panel) and ubiquitination-promoting activity using $\left[{ }^{35} \mathrm{~S}\right]$ methionine-labeled Gcn4 (top panel). Each ubiquitination reaction included $\sim 100 \mathrm{ng}$ of triple infection $\mathrm{SCF}^{\mathrm{cdc} 4}$ (see Materials and Methods). The bracket highlights the peak ubiquitination-promoting activities (fractions 3 and 5). (C) Ubiquitination reactions were carried out with $\left[{ }^{35} \mathrm{~S}\right]$ methionine-labeled Gcn 4 (lane 1) in the presence of triple infection $\mathrm{SCF}^{\mathrm{cdc} 4}$ and a fraction of yeast extract that was enriched for Gen 4 kinase activity (see Materials and Methods). Varying amounts $(5,10$, and $20 \mu \mathrm{g}$ ) of kinase fraction prepared from an $\operatorname{SRB10}(\mathrm{Z719}$, lanes 2-4) or an srb10s (Z687, lanes 5-7) strain were tested.

In our initial experiments to test the ability of Srb10 to phosphorylate Gcn4, we used a strain (Z689) that expressed HA-tagged Srb11, the cyclin partner of Srb10. Anti-HA immunoprecipitates from Z689 cells contained Gen4 kinase activity similar to that shown in Figure 3A (data not shown). $\left[{ }^{35}\right.$ S]methionine-labeled Gen4, after preincubation with an Srb11 $1^{\mathrm{HA}}$ immunoprecipitate, was ubiquitinated in the presence of purified Ubal, Cdc34, and $\mathrm{SCF}^{\mathrm{Cdc} 4}$ (Fig. 3C, lane 4). This reaction was specific because it was dependent on all of the above components and ubiquitin (lanes 2,5-8). Ubiquitination of Gcn4 by the $\mathrm{Cdc} 34 / \mathrm{SCF}^{\mathrm{Cdc} 4}$ pathway was also reconstituted with Gcn4 produced in E. coli (Fig. 3D). The greater reaction efficiency observed in this experiment was most likely owing to the use of SCF preparations containing Hrtl. Taken together, these results indicate that phosphorylation of Gen 4 by Srb10 promoted its recognition and ubiquitination by $\mathrm{SCF}^{\mathrm{Cdc} 4}$.

\section{Srb10 phosphorylates Gcn4 and regulates its stability in vivo}

To investigate the physiological relevance of our biochemical data, we first tested whether Srb10 influences the phosphorylation state of Gcn4 in vivo by evaluating the electrophoretic mobility of Gcn $4^{\text {myc9 }}$ immunoprecipitated from pulse-radiolabeled wild-type and srb10 mutant cells. Gcn4 was phosphorylated in vivo in an Srb10-dependent manner, as evidenced by a phosphatase-sensitive (Fig. 4A, right panel) molecular weight (MW) up-shift that was diminished in srb10 mutant cells (Fig. 4A, left panel). This, combined with our in vitro observations, strongly suggests that the Srb10 CDK is a physiological Gen4 kinase. If Srb10 targets Gen4 for turnover by the $\mathrm{SCF}^{\mathrm{Cdc} 4}$ pathway, we predicted that Gcn4 should be stabilized in srb10 mutants. To test this possibility, we carried out pulse-chase experiments to measure the turnover rate of $\mathrm{Gcn} 4^{\mathrm{myc} 9}$ in wild-type and srb10 mutants. It is important to note that the tagged Gcn4 was expressed from the endogenous GCN4 locus, under the control of the native promoter. Consistent with previously published results (Kornitzer et al. 1994; Meimoun et al. 2000), Gcn $4^{\mathrm{myc} 9}$ was rapidly degraded in wild-type cells, with a half-life of 2.5-5 min (Figs. 4B, 5B). In contrast, Gcn $4{ }^{\text {myc9}}$ was moderately stabilized in

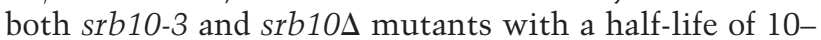
12 min (Figs. 4B, 5B). Consistent with this difference in half-life, the steady-state level of Gcn $4^{\mathrm{myc} 9}$ is about twofold higher in srb10 mutant cells compared to wild type (Fig. 4C). Careful examination of autoradiograms revealed that the phosphorylation-dependent up-shifted form of Gen $4^{\text {myc9 }}$ was strongly reduced, but not eliminated, in srb10 cells (Figs. 4B, 5A, 5B). Furthermore, Gcn $4^{\text {myc9 }}$ was more effectively stabilized in $c d c 34^{t s}$ cells at the restrictive temperature $\left(t_{1 / 2}>20\right.$ min; Fig. 4D). We thus inferred that there might be additional protein kinases that can target Gcn4 for degradation via the $\mathrm{Cdc} 34 / \mathrm{SCF}^{\mathrm{Cdc} 4}$ pathway.

\section{Both Srb10 and Pho85 contribute to Gcn4 turnover in vivo}

Meimoun et al. (2000) noted in their report that Gcn4 is not stabilized in an srb10-3 mutant. However, we reproducibly observed partial stabilization of Gen4 in srb10 mutants. Because Meimoun et al. performed their pulsechase analyses with overexpressed derivatives of Gen4, we evaluated whether overproduction influenced the ap- 
Chi et al.

Figure 3. Srb10 directly phosphorylates Gen 4 and targets it for $\mathrm{SCF}^{\mathrm{Cdc} 4}$-dependent ubiquitination. $(A)$ Immunoprecipitates from $S R B 10^{\text {myc9 }}$ strain YC6 (lanes 2, 6), KIN28 ${ }^{\text {myc9 }}$ strains YC15 (lanes 3, 7) and YC16 (lanes 4, 8), and untagged strain YC1 (lanes 1, 5) were assayed for kinase activity using, as substrate, Gcn4 (lanes 1-4) or GST-CTD (lanes 5-8) purified from $E$. coli. Reactions were evaluated by SDSPAGE and autoradiography. (B) Same as $A$, except immunoprecipitates from $S R B 10^{\text {myc9 }}$ strain $\mathrm{YC} 17$ (lane 2) and $s r b 10-3^{\text {myc9 }}$ strain YC7 (lane 4) were compared (top panel). Untagged strains Z719 (lane 1) and Z690 (lane 3) were used as controls. Antigen levels were monitored by immunoblotting duplicate immunoprecipitates with 9E10 antibody (bottom panel). (C) Srb10 protein kinase activity was immunoprecipitated from Z689 (SRB11 $1^{H A}$ ) with 12CA5 antibody. This immunoprecipitate had strong Gen4 kinase activity similar to the $S R B 10^{\text {mycs }}$ strains shown in $A$ and $B$ as judged by ${ }^{32} \mathrm{P}$ kinase assays (data not shown). The ubiquitination assay was carried out by first incubating $\left[{ }^{35} \mathrm{~S}\right]$ methionine-labeled Gcn 4 with Srb11 ${ }^{\mathrm{HA}}$ bound to protein A beads. An aliquot of the supernatant was used in the subsequent ubiquitination reactions (lanes 3-8). Immunoprecipitates from untagged strain Z719 were used as controls (lanes 1,2). Ubiquitination reactions were either supplemented with a complete set of components (lanes 2, 4) including SCF ${ }^{\mathrm{Cdc} 4}$ (triple infection) or a subset of components in which the factor indicated above each lane was omitted (lanes 5-8). (D) Gcn4 purified from E. coli was first phosphorylated in a kinase assay as shown in $B$, lane $2 .{ }^{32} \mathrm{P}$-Labeled Gcn4 was then added to ubiquitination reactions that were carried out as described in $C$, except $\mathrm{SCF}^{\mathrm{Cdc} 4}$ (quadruple infection) was used.
A

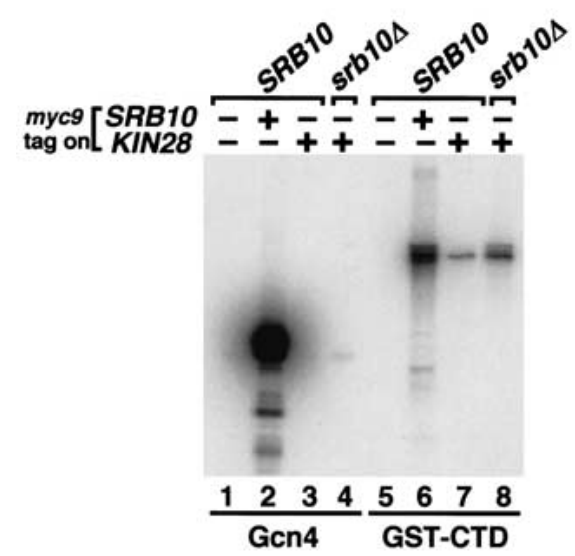

C

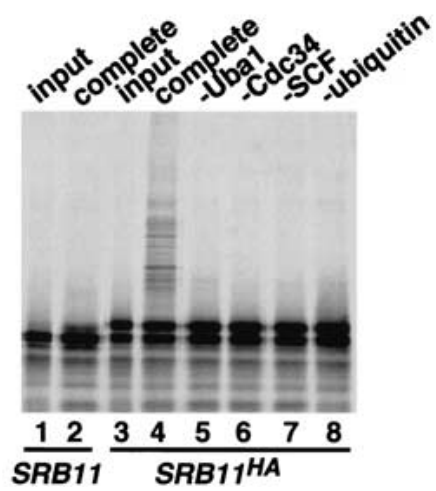

B

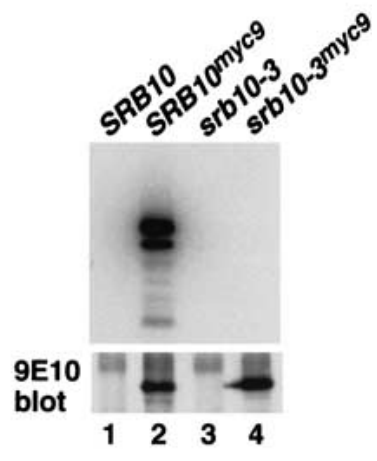

D

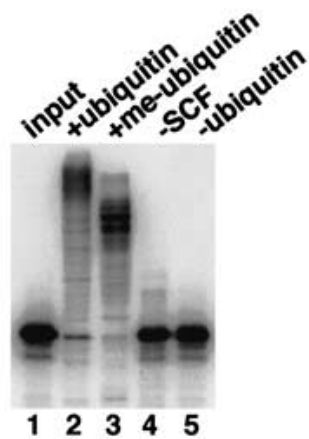

parent rate of Gcn4 degradation. To test this, we directly compared the rates of Gen $4^{\text {myc9 }}$ degradation in strains that expressed GCN4 ${ }^{\text {myc9 }}$ from a $G A L$ promoter with the strains that expressed $\mathrm{GCN} 4{ }^{\text {myc9}}$ from its own promoter. Indeed, when Gen $4^{\text {myc9 }}$ was overproduced, its rate of degradation appeared very similar in wildtype and $s r b 10 \Delta$ cells (Fig. 5A, top panels). At normal levels of expression, however, Gcn 4 was clearly stabilized in an srb10s mutant (Fig. 5A, bottom panels). Immunoblotting confirmed that the steady-state levels of Gen $4^{\text {myc9 }}$ were at least fivefold higher in $G A L$-driven GCN4 ${ }^{\text {myc9 }}$ strains compared with native-promoterdriven $G C N 4^{m y c 9}$ strains (data not shown). Interestingly, we also noticed a progressive, SRB10-independent posttranslational modification of Gcn $4^{\text {myc9 }}$ when it was overproduced (Fig. 5A, arrowhead; note that Gcn4 expressed from its own promoter does not show the same extent of progressive modification in srb10 cells), suggesting that the overexpressed protein is more susceptible to a protein kinase that normally does not act (or acts poorly) upon endogenously expressed Gcn4.

We evaluated Gcn $4^{\text {myc9 }}$ stability in several other CDK mutants in an attempt to address whether multiple CDKs play a redundant role in Gcn 4 turnover. Gcn $4{ }^{\text {myc9 }}$ degradation was unaffected in $\operatorname{ctk} 1 \Delta$ and $\alpha$-factor-ar- rested cells, suggesting that neither Ctk1 (a CDK homolog that phosphorylates CTD) nor Cdc28 contributed to turnover (data not shown). However, we found that Gcn $4{ }^{\text {myc9 }}$ was moderately stabilized in a pho85 $\Delta$ mutant with a half-life of about $20 \mathrm{~min}$ (Fig. 5B), similar to what was reported by Meimoun et al. (2000). To test whether Srb10 and Pho85 contribute independently to Gen4 turn-

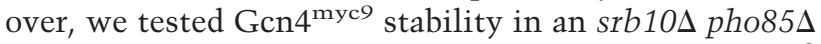
double mutant strain. As shown in Figure 5B, Gcn $4^{\text {myc9 }}$ was further stabilized in $s r b 10 \Delta$ pho85 $\Delta$ cells with a halflife $>40 \mathrm{~min}$, similar to what was observed in $c d c 34^{t s}$ cells at $37^{\circ} \mathrm{C}$ (Fig. 4D). Because srb10 and pho85 mutations had an additive effect, we conclude that at least two CDKs (Srb10 and Pho85) contribute to rapid Gcn4 turnover in vivo.

\section{Srb10-dependent degradation of Gcn4 is not regulated by amino acid starvation}

Because stabilization of Gcn 4 under amino acid starvation conditions is achieved at least in part by the downregulation of Pho85 activity (Meimoun et al. 2000), we wanted to test whether Srb10-dependent degradation of Gcn4 was regulated in a similar fashion. To test this, we 
A

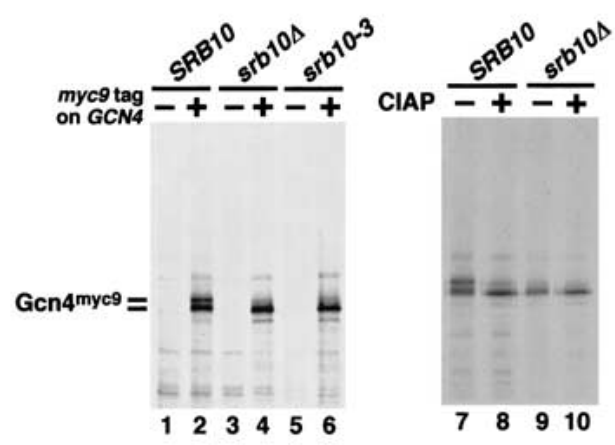

B
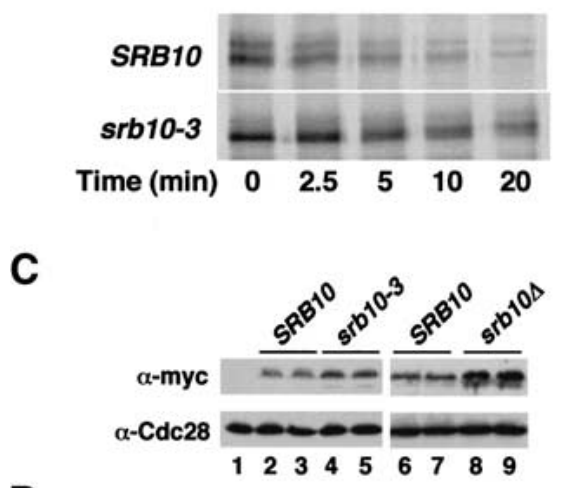

D

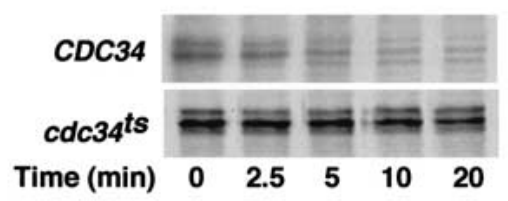

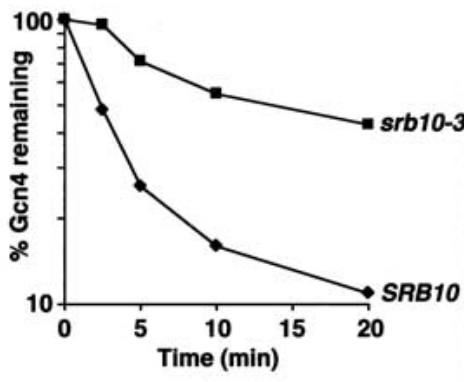

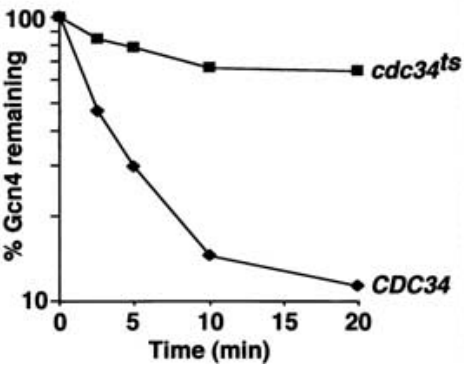

Figure 4. Srb10 phosphorylates Gen 4 and regulates its stability in vivo. (A) (Left panel) Cells from strains carrying untagged GCN4 (Z719, lane 1; Z687, lane 3; Z690, lane 5) or GCN4 ${ }^{\text {myc9 }}$ (YC19, lane 2; YC21, lane 4; YC45, lane 6) were pulse-labeled for $5 \mathrm{~min}$ (without chase) in SD medium containing Tran ${ }^{35}$ Slabel. Cell lysates were immunoprecipitated using 9E10 antibody and evaluated by SDS-PAGE and autoradiography as described in Materials and Methods. (Right panel) Same as left panel, except the immunoprecipitated samples were either mock-treated (lanes 7, 9) or treated (lanes 8, 10) with 2 U CIAP at $37^{\circ} \mathrm{C}$ for $30 \mathrm{~min}$. (B and $\left.D\right)$ Pulse-chase analysis of $\mathrm{Gen} 4^{\text {myc9 }}$ stability in SRB10 (YC19), srb10-3 (YC45), CDC34 (YC19), and cdc34 ${ }^{\text {ts }}$ (YC35) cells. Quantitations of the experiments are shown on the right. The experiment in $D$ was performed at $37^{\circ} \mathrm{C}$. (C) SRB10 (Z719, lane 1; YC19, lanes 2, 3, 6, 7), srb10-3 (YC45, lanes 4, 5), or $\operatorname{srb} 10 \Delta$ (YC21, lanes 8, 9) cells were cultured as described for the pulse-chase experiments, harvested, and lysed by boiling in SDS-containing buffer. Equal amounts $(-50 \mu \mathrm{g})$ of cell lysates were analyzed by immunoblotting using 9E10 (top panels) and anti-Cdc28 (bottom panels) antibodies. Each sample (except the untagged control) was run in duplicate lanes, and lanes 1-5 and 6-9 are from separate experiments. Bands were quantitated, and Gcn 4 signals were normalized against Cdc28. Compared to wild type, the Gcn4 level is 1.7 times higher in srb10-3 and 2.0 times higher in srb10s cells. imposed amino acid starvation conditions by culturing cells in minimal medium lacking a specific amino acid for which the cells were auxotrophic and then measured Gcn 4 stability under starved and unstarved conditions in wild-type, srb10s, and pho85s cells. Although Gcn $4^{\text {myc9 }}$ was significantly stabilized upon amino acid starvation with a half-life of about $20 \mathrm{~min}$ (Fig. 6A), it is further stabilized in srb10s cells with a half-life of about 40 min (Fig. 6B). Furthermore, Srb10-dependent phosphorylation of $\mathrm{Gcn} 4^{\mathrm{myc} 9}$ (as indicated by the molecular weight shift) was not diminished upon starvation (Fig. 6A,B), suggesting that it is not regulated by amino acid starvation. Whereas amino acid starvation significantly stabilized Gcn $4{ }^{\mathrm{myc} 9}$ further in srb10 $\Delta$ cells, it only increased Gcn $4^{\text {myc9 }}$ half-life slightly in pho85s cells (Fig. 6C). Taken together, these results suggest that Srb10 is not involved in the starvation-regulated aspect of Gen4 turnover, and down-regulation of Pho85 is the primary means of stabilizing Gcn 4 upon amino acid starvation.

\section{CDK phosphorylation is required for rapid Gcn4 turnover in vivo}

The protein sequence of Gcn 4 reveals five putative CDK phosphorylation sites (S/TP): S17, T61, T105, T165, and S218. Our analyses of Gcn 4 ubiquitination in vitro and stability in vivo suggest that these sites may be important for rapid Gen4 turnover. To test this possibility, we phosphorylated purified Gcn4 using Srb10 ${ }^{\text {myc9 }}$ immunoprecipitates and subjected the in vitro phosphorylated Gcn 4 to mass spectrometry analysis. All phosphopeptides that were recovered contained one of the five consensus S/TP sites. Moreover, direct sequencing confirmed that four of the consensus sites (S17, T61, T105, and S218) were phosphorylated. The exact site of phosphorylation on T165-containing peptides could not be determined, but was presumed to be T165. To analyze whether any of these sites is important for Gon 4 turnover, we first mutated each of the five sites by site-directed mutagenesis, and produced mutant forms of Gcn4 
Chi et al.

Figure 5. Both Srb10 and Pho85 contribute to Gen4 turnover in vivo. (A) Gen $4^{\text {myc9 }}$ stability under normal and overproduced conditions. Wild-type (YC19, YC23) and srb10s (YC21, YC24) cells grown in YPraffinose medium were transferred either to synthetic galactose medium (top two panels) or synthetic dextrose medium (bottom two panels) for $1 \mathrm{~h}$ prior to being subjected to pulse-chase analysis as described for Figure 4A. Quantitation of the results is shown on the right. The arrowhead denotes a posttranslationally modified form of Gcn $4^{\text {myc9 }}$ that appeared rapidly in SRB10 cells, but was only slowly generated in $s r b 10 \Delta$ strains. Note that the biphasic degradation observed for GALGCN4 ${ }^{\text {myc9 }}$ strains was likely owing to the carry-over synthesis of $\mathrm{Gcn} 4^{\mathrm{myc} 9}$ during the first $5 \mathrm{~min}$ of chase. (B) Gcn4 stability in wild-type (YC19), srb10s (YC21),

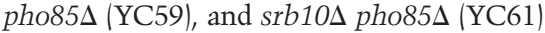
cells was evaluated by pulse-chase analysis (see Fig. 4A legend). Quantitation is shown on the right. In two independent experiments, the half-life of Gcn 4 in the various strains varied by less than $2 \mathrm{~min}$.
A
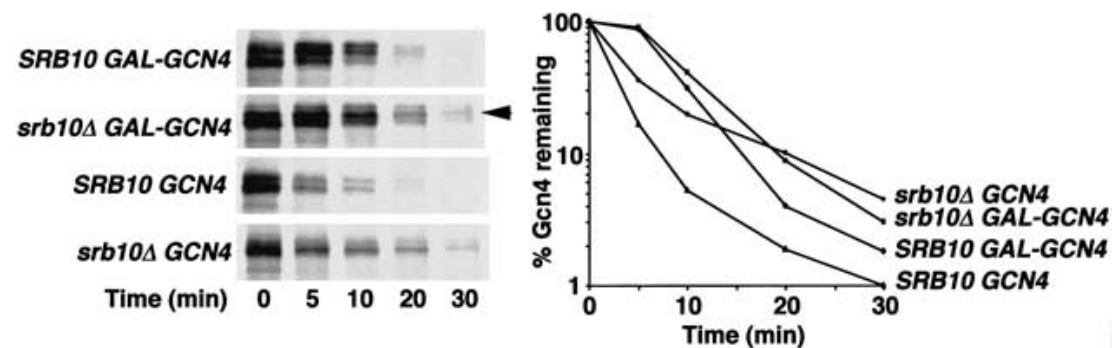

B
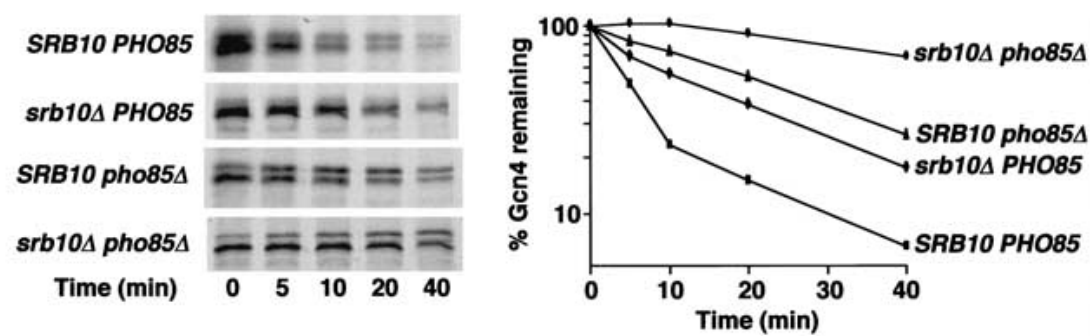

protein by in vitro translation. We then tested the ability of the five single and a quintuple (3T2S) phosphorylation-site mutants of Gen4 to serve as substrates for $\mathrm{SCF}^{\mathrm{Cdc} 4}$-dependent ubiquitination in vitro. Although we did not observe a marked defect for any of the single-site mutants, ubiquitination of the 3T2S quintuple mutant was greatly diminished (Y. Chi and R. Deshaies, unpubl.). Based on our in vitro data, we constructed a strain in which the wild-type GCN4 locus was replaced with gcn4-3T2 $S^{\text {myc9 }}$, and the stability of the encoded mutant protein was tested by pulse-chase analysis. As shown in Figure 7B, Gcn4-3T2S ${ }^{\text {myc9 }}$ was very stable in vivo, and there was no appreciable degradation during the 40-min chase period. Noticeably, the mutant protein did not exhibit the characteristic molecular weight shift caused by Srb10-dependent phosphorylation.

The gcn4-3T2 $S^{\text {myc9 }}$ strain did not show any obvious morphology or growth defect compared with wild type. Since we used a C-terminally myc9-tagged version of GCN4 for all of our in vivo studies, we were concerned that the myc9 tag might render Gen 4 inactive. To test the activities of various Gcn 4 derivatives in our strains, we employed a starvation plate assay similar to that described by Natarajan et al. (1999). Cells were streaked on
A

Figure 6. Srb10-dependent degradation of Gen4 is not regulated by amino acid starvation. (A) SRB10 (YC19) cells were grown to mid-log phase and transferred to either SD +leucine +histidine +uracil (starvation) or SD -leucine +histidine +uracil (+ starvation) medium. Cells were cultured for $15 \mathrm{~min}$, and pulse-chase analysis was carried out as described in Materials and Methods. Starving cells for 30 or 60 min resulted in similar magnitudes of stabilization of Gen 4 (data not shown). The half-life of Gen4 $\left(t_{1 / 2}\right)$ was determined from quantitation of the data using Phosphorimager. (B) Same as $A$, except SRB10 (YC19, top panel) and srb10s (YC21, bottom panel) cells were assayed for Gcn 4 stability in SD -leucine +histidine +uracil (+ starvation) cells only. (C) Same as $A$, except srb10s (YC21, top panels) cells and pho85s (YC59, bottom panels) cells were assayed for Gcn4 stability.
B
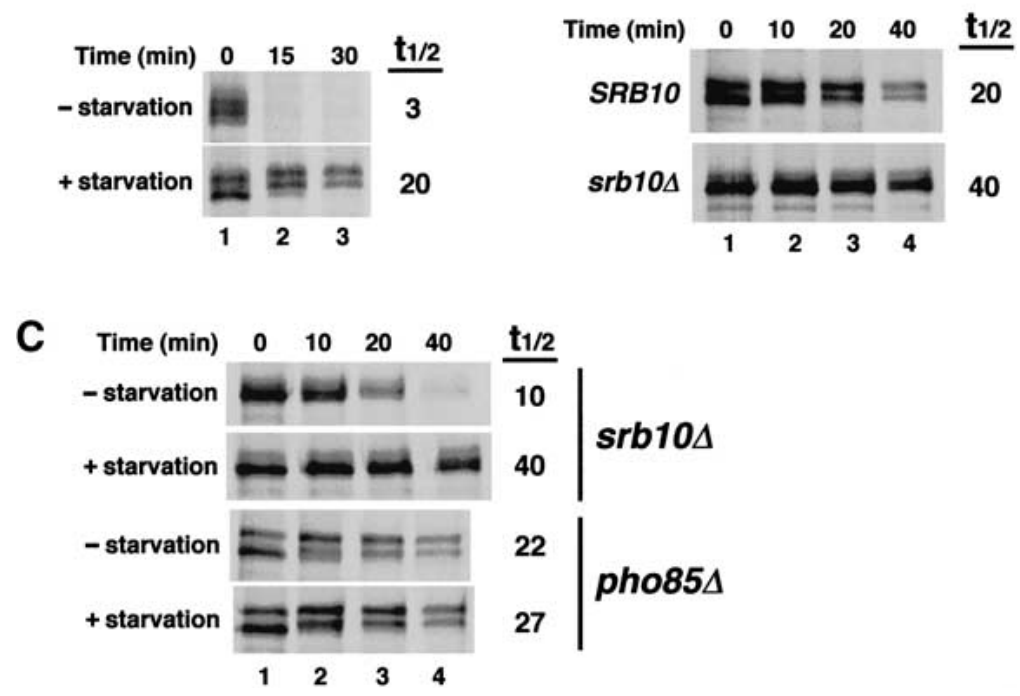
A

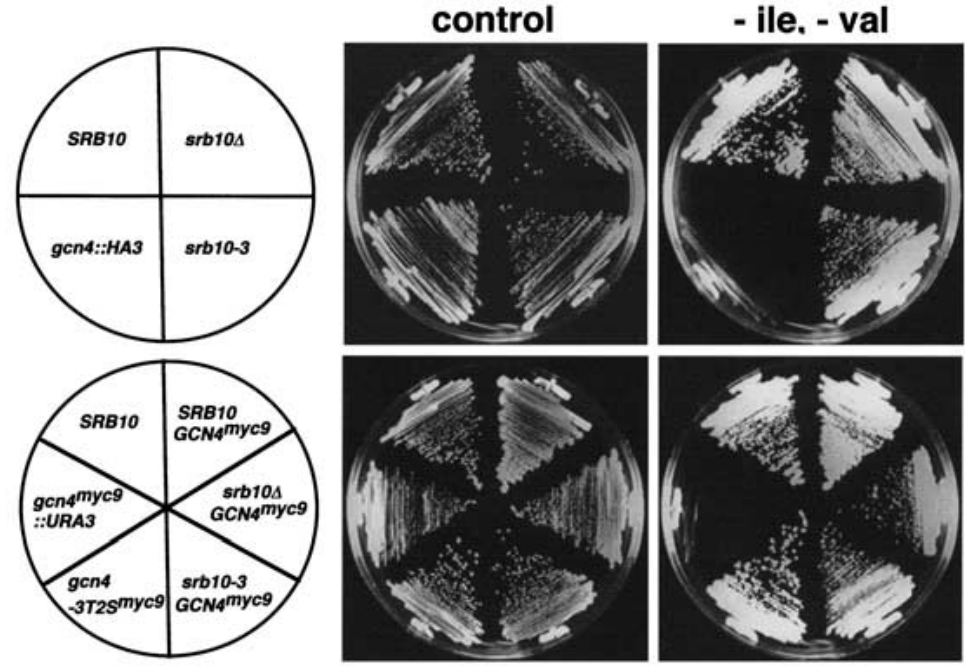

B

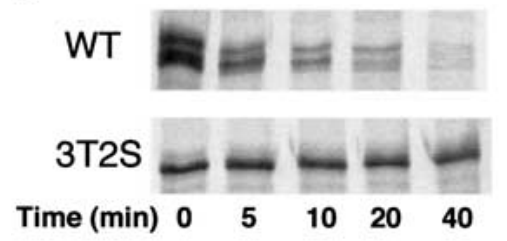

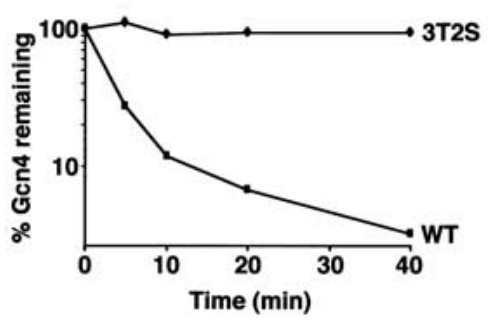

Figure 7. CDK phosphorylation is not essential for Gen4 activity, but is required for its rapid degradation in vivo. (A) Strains with the indicated genotypes were grown on SD +leu $(\sim 0.23 \mathrm{mM})$ +his +ura medium (control) and the same medium supplemented with $40 \mathrm{mM}$ leucine (-Ile, -Val) to induce starvation for isoleucine and valine. Plates were photographed after incubation at $30^{\circ} \mathrm{C}$ for $3 \mathrm{~d}$. (Top row of panels) Wild-type strain (Z719) and mutant strains srb10s (Z687), srb10-3 (Z690), and gcn4::HA3 (YC25). (Bottom row of panels) Strains containing myc9-tagged GCN4 alleles (YC19, YC21, YC45, YC57, and YC94). (B) Pulse-chase analysis (see Fig. 4A legend) of Gen $4^{\mathrm{myc} 9}$ stability in wild-type (YC19) and gcn43T2S (YC94) cells. Quantitation of the experiment is shown on the right. a control plate with normal leucine supplement and a plate with excess leucine, which causes isoleucine (Ile) and valine (Val) starvation (Niederberger et al. 1981). This assay monitors Gcn4-dependent activation of Ile and Val biosynthetic genes. As shown in Figure 7A, all strains (tagged or untagged GCN4) except gcn4 deletion mutants grew on -Ile, -Val plates equally well as on control plates, suggesting that the myc9 tag did not diminish the function of Gcn4. Furthermore, normal growth of gcn4-3T2S $S^{\text {myc9 }}$ cells on the starvation plate suggests that CDK phosphorylation is not essential for Gcn4 function.

\section{Srb10 phosphorylates Msn2 and influences its localization}

Microarray analysis of genomewide gene expression in the srb10-3 mutant reveals 173 genes whose expressions are up twofold or more than wild type, and a significant fraction of these genes are involved in stress response and diauxic shift (Holstege et al. 1998). Msn2 and Msn4 are two partially redundant zinc-finger transcription factors that activate expression of a suite of stress-response genes (Martinez-Pastor et al. 1996; Schmitt and McEntee 1996; Boy-Marcotte et al. 1998), including those induced in srb10-3 cells. Based on our analysis of Gen4 regulation, we hypothesized that Srb10 might also directly re- press the activities of transcription factors, including Msn2 and Msn4, by targeting them for degradation by the SCF pathway. To this end, we tested the ability of Msn2 to serve as a substrate for Srb10 in vitro. Using an assay similar to that shown in Figure 3A, we found Srb10 to be a potent kinase for recombinant GST-Msn2 (Fig. 8 A, lane 6). Furthermore, phosphorylated GST-Msn2 was efficiently ubiquitinated by $\mathrm{SCF}^{\mathrm{Cdc} 4}$ (data not shown). However, pulse-chase analysis revealed that Msn $2^{\text {myc9 }}$ was a stable protein in wild-type cells with a half-life of more than $1 \mathrm{~h}$ (data not shown). Interestingly, when pulsed-labeled at $27^{\circ} \mathrm{C}$ and chased under heat stress conditions $\left(37^{\circ} \mathrm{C}\right), \mathrm{Msn} 2$ was rapidly (within 5 min) phosphorylated in an SRB10-dependent manner (Fig. $8 \mathrm{~B})$. Taken together, these data suggest that Srb10 phosphorylates Msn2 in vivo in response to stress. However, Srb10-dependent phosphorylation did not appear to target Msn2 for degradation via the $\mathrm{Cdc} 34 / \mathrm{SCF}^{\mathrm{Cdc} 4}$ pathway.

Recent evidence suggests that Msn2 and Msn4 are regulated by shuttling between the cytoplasm and the nucleus in response to environmental conditions. Under normal conditions, Msn2 and Msn4 are retained in the cytoplasm, presumably by a combination of active nuclear export and cytoplasmic anchorage (Gorner et al. 1998; Beck and Hall 1999|. To test whether Srb10 influences the localization of Msn2/Msn4, we monitored Msn2 localization in $M S N 2^{\text {myc9 }}$ strains by indirect im- 
Chi et al.

Figure 8. Msn2 is phosphorylated in an Srb10-dependent manner in vitro and in vivo, and its localization is influenced by Srb10. (A) Kinase assays were carried out with purified GST (lanes 1, 2), GST-Gen4 (lanes 3, 4), and GST-Msn2 (lanes 5, 6) using immunoprecipitates from $S R B 10^{\text {myc9 }}$ strain $(\mathrm{YC17}$, lanes 2, 4, 6) and srb10$3^{\text {myc9 }}$ strain $(\mathrm{YC} 7$, lanes $1,3,5)$ as described in Figure 3A. (B) Cells from $M S N 2^{\text {myc9 }}$ (YC84, lanes 2-4) and MSN2 ${ }^{\text {myc9 }}$ srb10-3 (YC124, lanes 6-8) strains grown at $27^{\circ} \mathrm{C}$ were pulse-labeled with $\operatorname{Tran}^{35}$ Slabel at $27^{\circ} \mathrm{C}$ for 5 $\mathrm{min}$, and chased at $37^{\circ} \mathrm{C}$ for $5 \mathrm{~min}$. Aliquots $(1 / 3$ before the heat shock and 2/3 after the heat shock) of the cultures were subjected to immunoprecipitation with 9E10 antibody. Immunoprecipitates from the heat shock samples were divided and either mock-treated $($ lane 3, 7) or treated (lanes 4, 8) with 2 U CIAP for 30 min at $37^{\circ} \mathrm{C}$. Untagged strains Z719 (lane 1) and Z690 (lane 5) were used as controls. (C) Localization of Msn2 ${ }^{\text {myc9 }}$ in wild-type $(\mathrm{YC} 84, a), \operatorname{msn} 5 \Delta(\mathrm{YC} 107, b)$, and srb10-3 $(\mathrm{YC} 124, c)$ cells was evaluated under resting conditions by indirect immunofluorescence with 9E10 antibody. DAPI was used to stain cell nuclei. An srb10-3 strain containing untagged MSN2 (Z690) was used as control $(d)$.
A

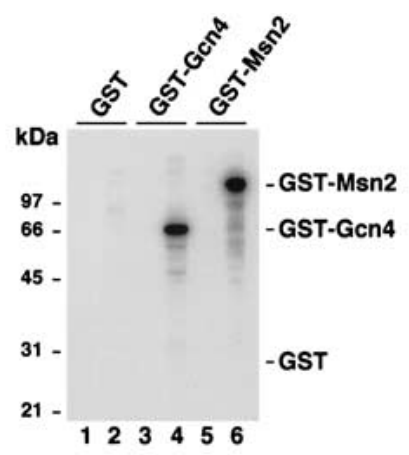

B

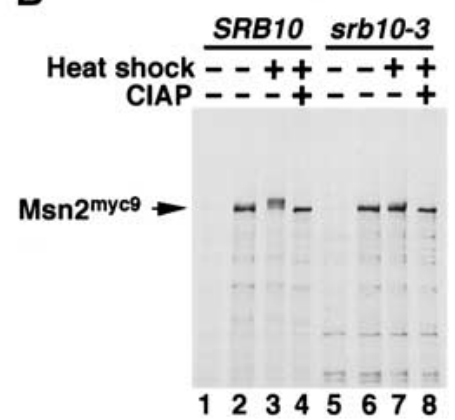

C

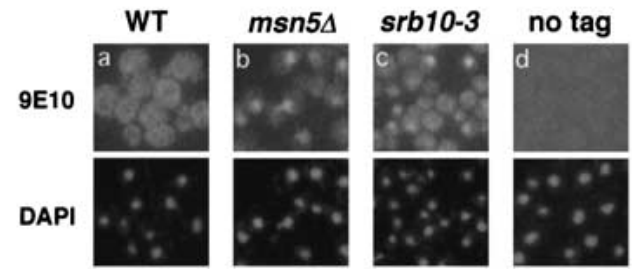

munofluorescence. As expected, Msn $2^{\text {myc9 }}$ was mostly cytoplasmic in wild-type cells under unstressed conditions (Fig.8C, panel a; Gorner et al. 1998). Interestingly, $\mathrm{Msn} 2^{\text {myc9 }}$ was localized to the nucleus in a subpopulation $(15 \%-30 \%)$ of unstressed srb10-3 cells (Fig. 8C, panel c) and srb10s cells (data not shown). Although we do not understand why Msn2 was mislocalized in only a fraction of $\operatorname{srb} 10 \Delta$ cells, our results are consistent with the elevated expression of MSN2/MSN4-dependent genes in srb10-3 cells as determined by microarray analysis of a population of cells (Holstege et al. 1998).

Because Msn5 has been shown to be a nuclear exporter for Pho4 that has been phosphorylated by Pho85 (Kaffman et al. 1998), we next tested whether Msn5 was also required for the export of Msn2. Strikingly, Msn2 ${ }^{\text {myc9 }}$ was concentrated in the nucleus in $>90 \%$ of $m s n 5 \Delta$ cells under normal conditions (Fig. 8C, panel b), suggesting that Msn5 is the primary export receptor for Msn2.

\section{Discussion}

SCF ubiquitin ligases have been implicated in the regulation of multiple transcription factors, including $\beta$-catenin, Gcn4, and Met4 (Deshaies 1999). Here, we provide four major lines of evidence that the Srb10 CDK complex of the SRB/mediator module of the RNA polymerase II holoenzyme contributes to Gen 4 instability by phosphorylating Gcn4 and thereby targeting it to $\mathrm{SCF}^{\mathrm{Cdc}}$. First, a high-molecular-weight Srb10-containing complex was purified as the most prominent activity in yeast extract that sustains $\mathrm{SCF}^{\mathrm{Cdc} 4}$-dependent ubiquitination of Gen4. Second, immunopurified Srb10 phosphorylated recombinant Gen4, thereby rendering it a substrate for recombinant SCF ${ }^{\text {Cdc4 }}$. Third, Gen 4 was phosphorylated in an SRB10-dependent manner in vivo.

Fourth, Gen4 was partially stabilized in srb10 mutants. Taken together, our observations indicate that Gcn4 is a physiological target of Srb10, and raise the intriguing possibility that recruitment of SRB/mediator may limit how long a transcriptional regulatory protein can occupy a promoter.

\section{Regulation of Gcn4 by Srb10 and Pho85}

During the course of our work, Meimoun et al. (2000) reported that Pho85 is required for rapid turnover of Gen4. Although they show that Gen4 is phosphorylated in vitro by recombinant Pcll/Pho85, there is no direct evidence that this modification triggers its ubiquitination by $\mathrm{SCF}^{\mathrm{Cdc}} 4$. It therefore remains possible that Pho 85 influences both Gen4 and Sic1 (Nishizawa et al. 1998; Meimoun et al. 2000) degradation through an indirect effect on $\mathrm{SCF}^{\mathrm{Cdc} 4}$ activity. Nevertheless, we favor the hypothesis that both Srb10 and Pho85 directly promote Gcn4 turnover, and that the kinases act independently to target Gcn4 degradation, based on the observation that

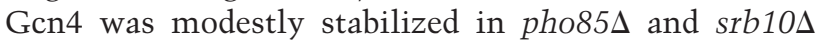

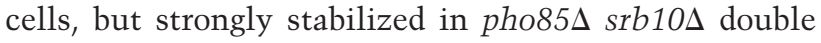
mutants. Our observations coupled with those of Meimoun et al. suggest that it may be possible to generate more sophisticated regulatory controls by making the SCF-dependent turnover of a substrate require its phosphorylation by two or more kinases. Because distinct protein kinases can target different substrates to a single type of SCF complex (e.g., $\mathrm{G}_{1}$-CDK targets Sic1, whereas either Srb10 or Pho85 targets Gcn4, to the $\mathrm{SCF}^{\mathrm{Cdc} 4}$ complex), and because there are potentially 17 different types of SCF complexes and 120 protein kinases in yeast, combinatorial interactions between these elements can potentially generate a staggering array of regulatory controls. 
Recent evidence suggests that amino acid starvation stabilizes Gcn4 through the negative regulation of Pho85-dependent phosphorylation (Meimoun et al. 2000). Interestingly, we found that Gcn4 was only moderately stabilized upon starvation and was further stabilized in srb10s cells. Moreover, Srb10-dependent phosphorylation of Gen4 remained intact in amino acidstarved cells (Fig. 6A,B). This indicates that whereas Pho85 is down-regulated upon starvation, Srb10-dependent degradation of Gcn 4 persists. It appears that Srb10 and Pho85 contribute to $\mathrm{SCF}^{\mathrm{Cdc} 4}$-dependent degradation of Gcn4 in different ways, either by targeting different pools of Gen 4 or by responding to different cellular signals.

If Srb10 negatively regulates Gcn4 by promoting its turnover, one would expect to see increased expression of Gcn 4 target genes in srb10 mutants. Although microarray analysis of genomewide gene expression in the srb10-3 mutant reveals 173 genes whose expressions are up twofold or more compared to wild type (Holstege et al. 1998), only two of these are potential Gcn4 targets. This suggests that srb10 mutation does not lead to global derepression of Gen 4 target genes under normal growth conditions. We provide the following possible reasons to explain the microarray data. First, stabilization of Gcn4 in srb10 mutants only leads to an $~ 1.5-2$-fold increase in the steady-state level of Gcn4 (Fig. 4C). Compensatory regulatory mechanisms, such as redundant kinases that promote Gcn 4 turnover and the well-characterized Gcn4 translational controls, may serve to limit the accumulation of Gcn4 in srb10 cells. The former possibility is supported by the observation that the 3T2S mutations have a greater effect on Gen 4 stability than does the pho85 srb10 double disruption (cf. Figs. 5B, 7B). Second, Srb10 may have self-canceling positive and negative effects on Gcn4. It is possible that phosphorylation of Gen4 by Srb10 stimulates its activity while also promoting its turnover. If so, the loss of Srb10dependent phosphorylation of Gcn 4 may not only stabilize the protein but also decrease its potency as a transcriptional activator. Third, pleiotropic effects of srb10 mutation, such as derepression of the stress response genes (Holstege et al. 1998) and slow growth, may indirectly alter the expression profile of Gcn 4 target genes. Despite the absence of major change in the transcriptional output of Gcn 4 in srb10 mutants, it is evident that Srb10 negatively regulates Gen 4 by promoting its rapid turnover.

\section{Regulation of Msn2 and Msn4 by Srb10}

The transcriptional activities of the partially redundant Msn2 and Msn4 proteins are tightly regulated. In resting cells these factors are inactive; whereas in stressed cells they promote transcription of a large suite of genes (Martinez-Pastor et al. 1996; Schmitt and McEntee 1996; Boy-Marcotte et al. 1998). Srb10 is implicated in the regulation of Msn2/Msn4, in that multiple transcriptional targets of these proteins are in- duced in srb10-3 cells (Holstege et al. 1998). Msn2 was phosphorylated by Srb10 in vitro, and the phosphorylation state of Msn2 was modulated by Srb10 in vivo (Fig. $8 \mathrm{~A}, \mathrm{~B})$. In contrast to Gcn4, however, Msn2 was stable in resting or stressed cells, regardless of whether it was localized to the cytoplasm or to the nucleus (data not shown).

Activation of Msn2 in stressed cells is linked to its translocation from the cytoplasm to the nucleus (Gorner et al. 1998). Whereas Msn2 is exclusively cytoplasmic in resting wild-type cells, Msn2 was primarily nuclear in $15 \%-30 \%$ of $s r b 10$ cells (Fig. $8 C$ ). Although our data show that SRB10 can influence Msn2 localization, other factors, including the TOR and cAMP-dependent protein kinases, govern the nucleocytoplasmic shuttling of Msn2 in stressed cells (Gorner et al. 1998; Beck and Hall 1999), and regulated trafficking of Msn2 still occurred properly in the majority of srb10 cells (data not shown). The underlying basis for the heterogeneity of srb10 cell populations is unclear. Perhaps the majority of srb10s cells adapt to chronic Msn activity in the nucleus by inducing factors that partially bypass Srb10's role in Msn2 export. Regardless of the exact relationship between stress, Msn2/Msn4, and Srb10, the most parsimonious hypothesis is that the global induction of Msn target genes in srb10-3 cells (Holstege et al. 1998) results, at least in part, from failure to properly phosphorylate and thereby promote Msn5-dependent export of Msn2/Msn4 from the nucleus. Mapping and mutation of Srb10 phosphorylation sites in Msn2 will be needed to vigorously establish a direct role for Srb10 in the nuclear export of Msn2.

\section{Implications for negative regulation of transcription by SRB/mediator: beyond CTD phosphorylation}

The Srb10/Srb11 CDK/cyclin pair is part of a heterotetrameric module, which associates with the multiprotein complex termed SRB/mediator (Myer and Young 1998). Current models suggest that the Srb10 module functions through CTD of RNA polymerase II, in part by controlling its phosphorylation (Hengartner et al. 1998). Both genetic and microarray analyses indicate that Srb10 serves as a negative effector of specific transcriptional programs (Carlson 1997; Holstege et al. 1998). These observations pose a key question, namely, how does Srb10 activity selectively repress the expression of a small subset of the genome? Biochemical studies revealed that phosphorylation of CTD by Srb10 blocked the recruitment of RNA polymerase holoenzyme to promoter DNA (Hengartner et al. 1998). It was postulated that gene-specific control by Srb10 might be mediated by promoterbound factors that influence whether or not Srb10/Srb11 phosphorylates CTD before a promoter-bound preinitiation complex is formed.

An expanded view for how Srb10 negatively regulates transcription of selected genes is supported by our work. Specifically, we propose that Srb10 directly phosphorylates transcription factors, thereby altering their activity. 
Chi et al.

This provides a simple and logical explanation for how Srb10 mediates gene-specific transcriptional regulation. Interestingly, the exact mechanism of regulation appears to differ for different transcription factors. Whereas Srb10 targets Gcn4 for $\mathrm{SCF}^{\mathrm{Cdc} 4}$-dependent degradation, it appears to down-regulate Msn2 activity by promoting nuclear exclusion (although the exact manner in which this occurs remains to be determined). In support of a direct role for Srb10 in the regulation of transcription factors, phosphorylation of the S699 residue of Gal4 by Srb10 was recently shown to be essential for Gal4-dependent induction of GAL genes (Hirst et al. 1999). Coupled with phosphorylation of the CTD, direct phosphorylation of specific transcription factors by Srb10 might potentiate its inhibitory effect on transcription and help focus its repressive activity upon specific promoters.

An interesting idea that emerges from our and other studies is that direct negative regulation of transcriptional activators by Srb10 may be confined to the vicinity of promoters to limit the lifetime of transcription factors that are actively engaged in promoting transcription. We propose that Srb10 comprises a timer that constitutively targets promoter-bound Gcn 4 for degradation to limit the number of transcripts that a DNA-bound molecule of Gcn 4 can promote. Intriguingly, analysis of a set of synthetic transcriptional activators revealed an inverse relationship between their potency and their stability, suggesting that the degradation of transcription factors may be mechanistically coupled to their ability to promote assembly of active transcriptional complexes on promoter DNA (Molinari et al. 1999). Thus, spatially restricted activation of transcription factor proteolysis may be a general regulatory theme. Note that a related argument can also be advanced for Msn2 and Msn4, whereby Srb10-dependent phosphorylation initiates the nuclear export of Msn molecules located at promoter elements. Although our studies highlight roles for Srb10 in the control of Gen4 stability and Msn2 export, it is possible that Srb10 modulates other aspects of transcription factor activity in a spatially restricted manner. It will be interesting to see if the mammalian homolog of Srb10 likewise mobilizes diverse regulatory strategies to enable tight regulation of gene expression.

\section{Materials and methods}

Yeast strains

The yeast strains used in this study are listed in Table 1. All YC strains were derived from Z719, Z690, and Z687 (Liao et al.

Table 1. Yeast strains

\begin{tabular}{|c|c|}
\hline Strain & Genotype \\
\hline \multirow{3}{*}{\multicolumn{2}{|c|}{ 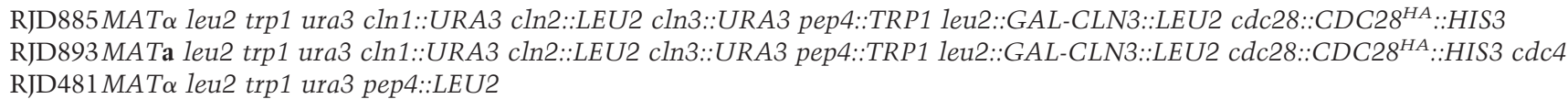 }} \\
\hline & \\
\hline & \\
\hline Z719 & MATa his3 $\Delta 200$ leu2-3,112 ura3-52 \\
\hline Z687 & 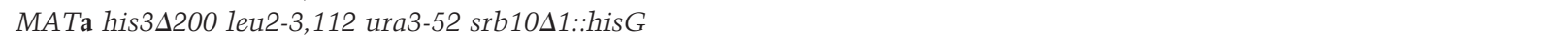 \\
\hline Z690 & MATa his3د200 leu2-3,112 ura3-52 srb10-3:hisG \\
\hline Z689 & MATa his3A200 leu2-3,112 ura3-52 srb114::hisG RY7038[SRB11 ${ }^{H A}$ CEN URA3] \\
\hline YC1 & MATa his3 200 leu2-3,112 ura3-52 GCN4 ${ }^{H A 3}$ \\
\hline YC2 & 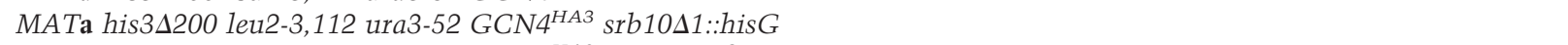 \\
\hline YC6 & MATa his3 200 leu2-3,112 ura3-52 GCN4 ${ }^{H A 3}$ SRB10 myc9 \\
\hline YC15 & MATa his3 3200 leu2-3,112 ura3-52 GCN4 ${ }^{\text {HA3 }}$ KIN28 ${ }^{\text {myc9 }}$ \\
\hline YC16 & 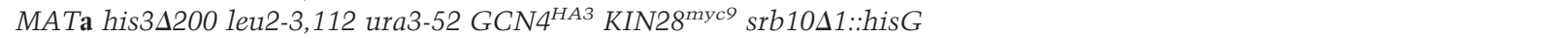 \\
\hline YC17 & MATa his3 $\Delta 200$ leu2-3,112 ura3-52 SRB10 myc9 \\
\hline YC7 & 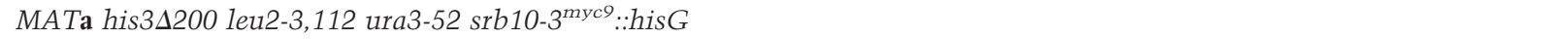 \\
\hline YC19 & MATa his3 $\Delta 200$ leu2-3,112 ura3-52 GCN4 ${ }^{\text {myc9 }}$ \\
\hline YC21 & 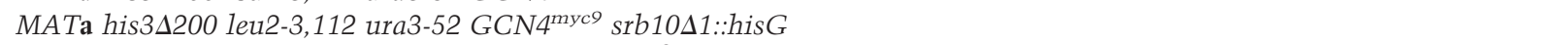 \\
\hline YC23 & MATa his34200 leu2-3,112 ura3-52 GAL-GCN4 ${ }^{\text {myc9 }}$ \\
\hline YC24 & 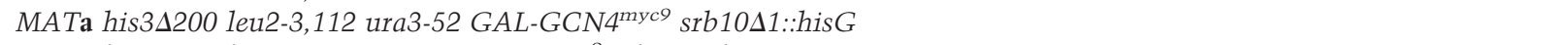 \\
\hline YC45 & MATa his3د200 leu2-3,112 ura3-52 GCN4 ${ }^{\text {myc9 }}$ srb10-3::hisG \\
\hline YC40 & MATa his34200 leu2-3,112 ura3-52 cdc34-2 \\
\hline YC35 & MATa his3 200 leu2-3,112 ura3-52 GCN4 ${ }^{\text {myc9 }}$ cdc34-2 \\
\hline YC67 & MATa his34200 leu2-3,112 ura3-52 pho85::URA3 \\
\hline YC59 & MATa his34200 leu2-3,112 ura3-52 GCN4 ${ }^{\text {myc9 }}$ pho85::URA3 \\
\hline YC69 & 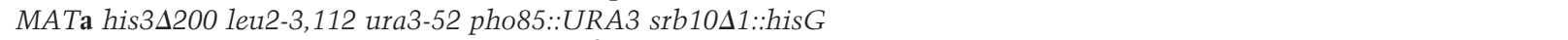 \\
\hline YC61 & 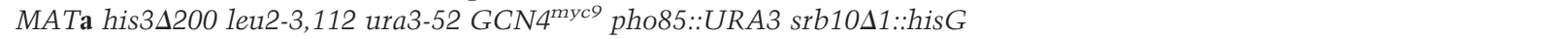 \\
\hline YC25 & MATa his3د200 leu2-3,112 ura3-52 gcn4::HA3 \\
\hline YC57 & MATa his34200 leu2-3,112 ura3-52 gcn4 ${ }^{\text {myc9 }}:: U R A 3$ \\
\hline YC94 & MATa his34200 leu2-3,112 ura3-52 gcn4-3T2S ${ }^{\text {myc9 }}$ \\
\hline YC84 & MATa his3د200 leu2-3,112 ura3-52 MSN2 ${ }^{\text {myc9 }}$ \\
\hline YC124 & MATa his34200 leu2-3,112 ura3-52 MSN2 ${ }^{\text {myc9 }}$ srb10-3::hisG \\
\hline YC111 & MATa his3 200 leu2-3,112 ura3-52 msn5::URA3 \\
\hline YC107 & MATa his34200 leu2-3,112 ura3-52 MSN2 ${ }^{\text {myc9 }}$ msn5::URA3 \\
\hline
\end{tabular}


1995). Yeast cells were cultured in standard rich or synthetic medium supplemented with $2 \%$ dextrose, raffinose, or galactose as described (Sherman 1991). The GCN4 locus was modified to encode Gcn 4 tagged with three copies of the HA epitope (HA3) at its $\mathrm{C}$ terminus as described (Schneider et al. 1995), and a $g c n 4$ deletion strain ( $g c n 4:: H A 3)$ was generated using a similar scheme. The GCN4, SRB10, srb10-3, KIN28, and MSN2 loci were modified to encode proteins tagged with nine copies of the myc epitope (myc9) at their $\mathrm{C}$ termini as described (Seol et al. 1999). GAL-GCN4 alleles were generated by replacement of the entire GCN4 promoter region with a PCR fragment containing URA3 and GAL1, 10 promoter sequences. cdc34ts strains were constructed by homologous recombination using a plasmid carrying cdc34-2 (Kornitzer et al. 1994). The gcn4, pho85, and msn5 deletion strains were generated by PCR-based one-step replacement. Deletion alleles were confirmed by scoring mutant phenotypes and by PCR. To generate the gcn4$3 T 2 S^{\text {myc9 }}$ strain, sequences spanning the five SP/TP sites within $G C N 4^{\text {myc9 }}$ were first replaced by URA3. The resulting $G C N 4^{\text {myc9 }}:: U R A 3$ strain was subsequently transformed with a gcn4-3T2S fragment that also contained adjacent 5' untranslated sequences. Transformants were cultured in YPD for 6-10 $\mathrm{h}$ prior to plating on 5 -fluoroorotic acid (5-FOA) medium. 5-FOA-resistant transformants were screened by PCR and confirmed by sequencing. All strains derived from Z719, Z690, or Z687 were constructed either by direct transformation using lithium acetate method or by genetic cross. Details of the strain constructions or oligonucleotide sequences are available upon request.

\section{Fractionation of yeast extracts}

Whole cell or DEAE Sepharose FF (Amersham Pharmacia) fractions of yeast extracts from $G_{1}$ cyclin-depleted RJD885 or RJD893 cells were prepared as described (Verma et al. 1997b) with the following modifications. After the frozen cell powder was thawed in Buffer93 (B93), saturated (100\%) ammonium sulfate solution was added slowly to a final concentration of $10 \%$ to allow further extraction of proteins. To concentrate fractionated proteins prior to assay, the flow-through and 0.15-0.25 M $\mathrm{NaCl}$ eluate of the DEAE Sepharose column were concentrated (to $\sim 30 \mathrm{mg} / \mathrm{mL}$ ) using an Ultrafree-15 centrifugal filter (Biomax10K, Millipore) and dialyzed against B93.

To resolve Gcn4 kinase and ubiquitination activities, RJD893 whole-cell extract (WCE) was first fractionated by ammonium sulfate precipitation. The $0 \%-35 \%$ and the $45 \%-60 \%$ cuts were resuspended in CWB (25 mM HEPES at pH 7.6, $25 \mathrm{mM} \mathrm{NaCl}$, and $1 \mathrm{mM}$ DTT) and applied to a DEAE Sepharose column. The $0.25 \mathrm{M}$ eluate from each DEAE fractionation was concentrated to $10-15 \mathrm{mg} / \mathrm{mL}$ and dialyzed against B93. The $0.25 \mathrm{M} \mathrm{DEAE}$ eluate from the $0 \%-35 \%$ ammonium sulfate cut contained Gcn 4 kinase activity, whereas that from the $45 \%-60 \%$ cut contained Gen 4 ubiquitination activity (when supplemented with the kinase fraction plus Cdc34). For assays shown in Figure 2C, the dialyzed $0 \%-35 \%$ ammonium sulfate cut was used directly without further purification.

To partially purify the Gcn 4 kinase, we grew RJD481 cells in YPD to late $\log$ phase (optical density at $600 \mathrm{~nm}, \mathrm{OD}_{600}=2.5-3$ ) and harvested and lysed them as described (Verma et al. 1997b). Whole cell extract ( 1000 mg protein) was first fractionated by ammonium sulfate precipitation, and the $0 \%-40 \%$ cut $/ \sim 150$ $\mathrm{mg}$ protein) was resuspended in CWB and loaded onto a $10-\mathrm{mL}$ SP Sepharose FF (Amersham Pharmacia) column. The column was washed with $30 \mathrm{~mL} \mathrm{CWB}$ and eluted with a 100-500 mM $\mathrm{NaCl}$ gradient. Fractions containing the peak activity (as measured by kinase and ubiquitination assays, see below) were pooled ( $7 \mathrm{mg}$ protein), diluted in $\mathrm{CWB}$, and applied to $2 \mathrm{~mL}$ of glutathione agarose (Sigma) previously loaded with $\sim 4 \mathrm{mg}$ GSTGcn 4 . The affinity column was washed with $5 \mathrm{~mL}$ of CWB +100 $\mathrm{mM} \mathrm{NaCl}$ and eluted with $4 \mathrm{~mL}$ of $\mathrm{CWB}+400 \mathrm{mM} \mathrm{NaCl}$. The eluate was concentrated to $200 \mu \mathrm{L}(-300 \mu \mathrm{g}$ protein), and $50 \mu \mathrm{L}$ was loaded onto a 2.4-mL Superdex200 column (Amersham Pharmacia) equilibrated with $\mathrm{CWB}+500 \mathrm{mM} \mathrm{NaCl}$. Fractions of volume $50 \mu \mathrm{L}$ were collected, and $2 \mu \mathrm{L}$ of each fraction was used in the activity assays.

\section{Preparation of assay substrates}

GCN4 and SIC1 were transcribed from EcoRI-linearized YEp88GCN4 and RDB445 by SP6 and T7 polymerase, respectively. A GCN4-HA transcription template was generated by PCR using a 5' oligonucleotide containing a T7 RNA polymerase promoter (Verma et al. 1997b) and a 3' oligonucleotide containing sequences that encode the HA epitope. All mRNAs were translated in rabbit reticulocyte lysates according to manufacturer's instructions (Promega). For ubiquitination assays, in vitrotranslated Gen 4 was partially purified by batch chromatography on DEAE resin as described for Sicl (Verma et al. 1997c). The 100-400 mM NaCl DEAE eluate containing Gcn4 was heated at $65^{\circ} \mathrm{C}$ for $5 \mathrm{~min}$ to destroy a nonspecific Gen 4 kinase activity present in reticulocyte lysates (brief heating at up to $90^{\circ} \mathrm{C}$ did not significantly compromise the ability of Gen 4 to serve as a ubiquitination substrate). The eluate was then centrifuged at $10,000 \mathrm{~g}$ for $5 \mathrm{~min}$, and the supernatant was exchanged into 30 $\mathrm{mM}$ Tris- $\mathrm{HCl}$ at $\mathrm{pH} 7.5,50 \mathrm{mM}$ potassium acetate, and $1 \mathrm{mM}$ DTT by three cycles of dilution and concentration to the original volume in a Centricon-10 (Amicon). Recombinant Gcn4 was also expressed in E. coli and purified as described (Kim et al. 1994). GST, GST-Gen4, and GST-Msn2 were expressed in BL21(DE3) containing pLyS, and were purified by glutathione affinity chromatography. GST-CTD was expressed and purified as described (Thompson et al. 1993).

\section{Immunoprecipitations, kinase assays, and immunoblots}

Active protein kinases were isolated from yeast strains in which the relevant genes were modified to encode proteins with a myc9 epitope at the $\mathrm{C}$ terminus. Cells were grown to late $\log$ phase $\left(\mathrm{OD}_{600}=2.5-3\right)$, and whole cell extracts were prepared as described above. All purification procedures were performed on ice or at $4^{\circ} \mathrm{C}$. Typically, cell extract $(200-300 \mu \mathrm{L}$ of $30-40 \mathrm{mg} /$ $\mathrm{mL}$ ) was diluted three-fold with Buffer B ( $30 \mathrm{mM}$ Tris- $\mathrm{HCl}$ at $\mathrm{pH}$ 7.5, 6\% ammonium sulfate, $1 \mathrm{mM}$ EDTA, $1 \mathrm{mM}$ DTT, $0.02 \%$ Triton X-100, and $0.5 \mathrm{mM}$ PMSF), and preincubated with $15 \mu \mathrm{L}$ protein A beads for $1 \mathrm{~h}$. After brief centrifugation, the supernatant was incubated with $1 \mu \mathrm{L}$ of anti-myc monoclonal antibody in 9E10 ascites fluid for $2 \mathrm{~h}$ and then with $10-15 \mu \mathrm{L}$ of protein A beads for an additional $1-2 \mathrm{~h}$. The protein $\mathrm{A}$ beads were washed three times with Buffer B and once with kinase assay buffer (KAB: $30 \mathrm{mM}$ Tris- $\mathrm{HCl}$ at $\mathrm{pH}$ 7.5, $10 \mathrm{mM} \mathrm{MgCl} 2,10 \mathrm{mM}$ $\mathrm{NaCl}, 1 \mathrm{mM}$ DTT, and $0.02 \%$ Triton X-100).

${ }^{32} \mathrm{P}$ kinase assays were performed by incubating immobilized kinase with $1 \mu \mathrm{g}$ substrate (Gen4, GST, GST-CTD or GSTMsn2) in a $10-\mu \mathrm{L}$ reaction containing KAB, $0.5 \mu \mathrm{L} \gamma-{ }^{32} \mathrm{P}$-ATP $(4500 \mathrm{Ci} / \mathrm{mmole})$, and $50 \mu \mathrm{M}$ ATP at $22^{\circ} \mathrm{C}$ for $1 \mathrm{~h}$ with occasional mixing. The reaction was briefly centrifuged, and the supernatant was either used immediately as substrate for the ubiquitination reactions (Figs. 3D) or mixed with Laemmeli sample buffer, boiled for $3 \mathrm{~min}$, resolved by SDS-PAGE, and visualized by autoradiography. For $\left[{ }^{35} \mathrm{~S}\right]$ methionine-labeled 
Chi et al.

Gcn4 substrates, kinase assays (Figs. 1B and 3C) were carried out for $30 \mathrm{~min}$ at $25^{\circ} \mathrm{C}$ in $\mathrm{KAB}$ supplemented with ATP regenerating system.

Immunoblotting was performed with either monoclonal 9E10 ascites fluid (1:2000 dilution) or affinity-purified anti-Cdc28 polyclonal antibody. Blots were visualized using horseradish peroxidase-conjugated secondary antibodies and a chemiluminescence $(\mathrm{ECL}+)$ kit (Amersham). For the experiment illustrated in Figure 4C, blots were scanned and quantitated using the STORM system (Molecular Dynamics).

\section{Ubiquitination assays}

Ubiquitination reactions in yeast extracts (Verma et al. 1997c) or with purified components (Feldman et al. 1997; Seol et al. 1999) were carried out essentially as described. Two forms of $\mathrm{SCF}^{\mathrm{Cdc} 4}$ were used during the course of this study: a triple infection complex (Skp1/Cdc53 ${ }^{\mathrm{PyHA}} / \mathrm{Cdc} 4^{\mathrm{PyHA}}$ ) and a quadruple infection complex (Hrt1/Skp1/Cdc53/Cdc4 $4^{\mathrm{PyHA}}$ ), both of which were expressed in baculovirus-infected Sf 9 insect cells, purified by binding to anti-polyoma $(\alpha-\mathrm{Py})$-conjugated protein A beads, and eluted using Py peptide as described (Seol et al. 1999). Approximately $100-150 \mathrm{ng}$ of $\mathrm{SCF}^{\mathrm{Cdc} 4}$ as estimated by Coommassie-stained gels was used in each reaction. Reactions were incubated at $25^{\circ} \mathrm{C}$ for $1 \mathrm{~h}$, terminated by addition of Laemmeli sample buffer, and evaluated by SDS-PAGE and autoradiography.

\section{Pulse-chase experiments}

$G C N 4^{m y c 9}, M S N 2^{m y c 9}$, and untagged control cells were grown overnight in SD+leucine+histidine+uracil at $30^{\circ} \mathrm{C}$ to mid-log phase $\left(\mathrm{OD}_{600}=\sim 0.5\right)$. Approximately $3 \times 10^{8}$ cells were harvested and concentrated by centrifugation into $3 \mathrm{~mL}$ of the same medium. Cells were pulse-labeled for $5 \mathrm{~min}$ with $500 \mu \mathrm{Ci}$ of $\operatorname{Tran}^{35} \mathrm{~S}$ label (1175 Ci/mmole, ICN), then chased in the same medium containing $1 \mathrm{mM}$ ammonium sulfate, $5 \mathrm{mM}$ methionine, and $1 \mathrm{mM}$ cysteine. For cdc34-2 mutants, cells were shifted to $37^{\circ} \mathrm{C}$ for $1 \mathrm{~h}$ before labeling. At various times of the chase, $0.5 \mathrm{~mL}$ of the culture was removed and diluted immediately into $1.5 \mathrm{~mL}$ cold stop buffer $(50 \mathrm{mM}$ Tris- $\mathrm{HCl}$ at $\mathrm{pH} 7.5,50$ $\mathrm{mM} \mathrm{NaF}$, and $0.1 \% \mathrm{NaN}_{3}$ ). Cells were centrifuged briefly, and cell pellets were frozen in liquid nitrogen (and stored at $-80^{\circ} \mathrm{C}$ if necessary). The cell pellets were then each supplemented with $100 \mu \mathrm{L}$ of $0.5 \mathrm{~mm}$ glass beads and $100 \mu \mathrm{L}$ of lysis buffer $(30 \mathrm{mM}$ Tris- $\mathrm{HCl}$ at $\mathrm{pH} 7.5,0.5 \%$ SDS, $6 \%$ ammonium sulfate, $1 \mathrm{mM}$ EDTA, $1 \mathrm{mM}$ DTT, and $0.5 \mathrm{mM}$ PMSF), vortexed for $2 \mathrm{sec}$, and boiled for $3 \mathrm{~min}$. The samples were cooled briefly, vortexed for $2 \mathrm{~min}$, boiled again for $2 \mathrm{~min}$, and vortexed again for $1 \mathrm{~min}$. Samples were then centrifuged at $10,000 \mathrm{~g}$ for $10 \mathrm{~min}$, and the supernatant was diluted fivefold with Triton buffer $(30 \mathrm{mM}$ Tris- $\mathrm{HCl}$ at $\mathrm{pH} 7.5,1 \%$ Triton $\mathrm{X}-100,1 \mathrm{mM}$ DTT, and $1 \mathrm{mM}$ PMSF) and immunoprecipitated with 9E10 antibody and protein $A$ beads. The protein $A$ beads were washed three times with Buffer B, aspirated to dryness, and mixed with $2 \times$ Laemmeli buffer. Samples were boiled for 3 min prior to being evaluated by SDS-PAGE, followed by autoradiography and PhosphorImager (Molecular Dynamics) analysis.

\section{ESMS Analysis of phosphorylated Gcn4}

Phospho-Gen4 (70 pmol) was digested with modified trypsin (Promega) for $6 \mathrm{~h}$ at $37^{\circ} \mathrm{C}$ and then subjected to multidimensional phosphopeptide analysis by ESMS (Verma et al. 1997a).
Briefly, phosphopeptides were detected by on-line LC-ESMS. The flow from the column was split, with $95 \%$ going to a fraction collector and $5 \%$ to the mass spectrometer. The mass spectrometer is optimized to produce and detect CID-generated $\mathrm{m} / \mathrm{z}$ $79\left(\mathrm{PO}^{3-}\right)$ product ions, which are highly specific for phosphorylated peptides (Huddleston et al. 1993). The MS is operated in a single ion-monitoring mode for enhanced sensitivity. Phosphopeptide-containing HPLC fractions (containing $\mathrm{m} / \mathrm{z} 79$ ions) were then analyzed by negative-ion nanoelectrospray, using precursor ion scans to distinguish phosphopeptides from unmodified peptides and determine their mass (Carr et al. 1996). Candidate phosphopeptides were sequenced by tandem mass spectrometry using nanoES (Carr et al. 1996) or on LC-ES MS/MS (Zhang et al. 1998). Phosphorylation site stoichiometry was determined by measuring the ratio of phosphorylated to nonphosphorylated peptide in the positive ion ES spectrum. Positive ion spectra for each phosphorylated and nonphosphorylated peptide were extracted and summed from a full scan LC-MS analysis of 18 pmoles of Gen4 tryptic digest.

\section{Immunofluorescence}

Cells were grown overnight in $30 \mathrm{ml} \mathrm{YPD}$ at $27^{\circ} \mathrm{C}$ to mid-log phase $\left(\mathrm{OD}_{600}=\sim 0.5\right), 4 \mathrm{~mL}$ of cells were then removed and fixed with $4.5 \%$ formaldehyde at room temperature for $1 \mathrm{~h}$. Indirect immunofluorescence was carried out essentially as described (Pringle et al. 1991), using 9E10 (1:3000) as primary antibodies and fluorescein-conjugated-goat-anti-mouse antibodies $(1: 3000)$ as secondary antibodies. Fujichrome Provia 400 slide film was used to record data images on a Zeiss Axioskop microscope.

\section{Acknowledgments}

We thank K. Struhl, R. Kornberg, D. Kornitzer, R. Feldman, G. Reynard, C. Correll, and J.H. Seol for supplying plasmids, strains, and baculovirus-expressed proteins. We thank R. Conaway and M. Petroski for comments on the manuscript. This work was financed in part by a grant from the NIH (GM52466), and support from the Lucille P. Markey Charitable Trust and the Howard Hughes Medical Institute (all to R.J. Deshaies) Y. Chi was supported by a National Research Service Award (T32GM07616) from the National Institute of General Medical Sciences.

The publication costs of this article were defrayed in part by payment of page charges. This article must therefore be hereby marked "advertisement" in accordance with 18 USC section 1734 solely to indicate this fact.

\section{References}

Bai, C., Sen, P., Hofmann, K., Ma, L., Goebl, M., Harper, J.W., and Elledge, S.J. 1996. SKP1 connects cell cycle regulators to the ubiquitin proteolysis machinery through a novel motif, the F-box. Cell 86: 263-274.

Beck, T. and Hall, M.N. 1999. The TOR signalling pathway controls nuclear localization of nutrient-regulated transcription factors. Nature 402: 689-692.

Boy-Marcotte, E., Perrot, M., Bussereau, F., Boucherie, H., and Jacquet, M. 1998. Msn2p and Msn4p control a large number of genes induced at the diauxic transition which are repressed by cyclic AMP in Saccharomyces cerevisiae. J. Bacteriol. 180: 1044-1052.

Carlson, M. 1997. Genetics of transcriptional regulation in 
yeast: Connections to the RNA polymerase II CTD. Annu. Rev. Cell Dev. Biol. 13: 1-23.

Carr, S.A., Huddleston, M.J., and Annan, R.S. 1996. Selective detection and sequencing of phosphopeptides at the femtomole level by mass spectrometry. Anal. Biochem. 239: 180192.

Ciechanover, A., Orian, A., and Schwartz, A.L. 2000. Ubiquitinmediated proteolysis: Biological regulation via destruction. Bioessays 22: 442-451.

Deshaies, R.J. 1999. SCF and cullin/RING H2-based ubiquitin ligases. Annu. Rev. Cell Dev. Biol. 15: 435-467.

Drury, L.S., Perkins, G., and Diffley, J.F. 1997. The Cdc4/34/53 pathway targets Cdc6p for proteolysis in budding yeast. EMBO J. 16: 5966-5976.

Elsasser, S., Chi, Y., Yang, P., and Campbell, J.L. 1999. Phosphorylation controls timing of Cdc6p destruction: A biochemical analysis. Mol. Biol. Cell 10: 3263-3277.

Feldman, R.M., Correll, C.C., Kaplan, K.B., and Deshaies, R.J. 1997. A complex of Cdc4p, Skplp, and Cdc53p/cullin catalyzes ubiquitination of the phosphorylated CDK inhibitor Siclp. Cell 91: 221-230.

Gorner, W., Durchschlag, E., Martinez-Pastor, M.T., Estruch, F., Ammerer, G., Hamilton, B., Ruis, H., and Schuller, C. 1998. Nuclear localization of the $\mathrm{C} 2 \mathrm{H} 2$ zinc finger protein Msn2p is regulated by stress and protein kinase A activity. Genes \& Dev. 12: 586-597.

Henchoz, S., Chi, Y., Catarin, B., Herskowitz, I., Deshaies, R.J., and Peter, M. 1997. Phosphorylation- and ubiquitin-dependent degradation of the cyclin-dependent kinase inhibitor Farlp in budding yeast. Genes \& Dev. 11: 3046-3060.

Hengartner, C.J., Myer, V.E., Liao, S.M., Wilson, C.J., Koh, S.S., and Young, R.A. 1998. Temporal regulation of RNA polymerase II by Srb10 and Kin28 cyclin-dependent kinases. Mol. Cell 2: 43-53.

Hinnebusch, A.G. 1992. General and pathway-specific regulatory mechanisms controlling the synthesis of amino acid biosynthetic enzymes in Saccharomyces cerevisiae. In The yeast Saccharomyces: Gene expression (ed. E.W. Jones et al.), pp. 319-414. Cold Spring Harbor Laboratory Press, Cold Spring Harbor, NY.

Hirst, M., Kobor, M.S., Kuriakose, N., Greenblatt, J., and Sadowski, I. 1999. GAL4 is regulated by the RNA polymerase II holoenzyme-associated cyclin-dependent protein kinase SRB10/CDK8. Mol. Cell 3: 673-678.

Holstege, F.C., Jennings, E.G., Wyrick, J.J., Lee, T.I., Hengartner, C.J., Green, M.R., Golub, T.R., Lander, E.S., and Young, R.A. 1998. Dissecting the regulatory circuitry of a eukaryotic genome. Cell 95: 717-728.

Huddleston, M.J., Annan, R.S., Bean, M.F., and Carr, S.A. 1993. Selective detection of phosphopeptides in complex mixtures by electrospray LC-MS. J. Am. Soc. Mass Spectrom. 4: 710717.

Jackson, P.K., Eldridge, A.G., Freed, E., Furstenthal, L., Hsu, J.Y., Kaiser, B.K., and Reimann, J.D. 2000. The lore of the RINGs: Substrate recognition and catalysis by ubiquitin ligases. Trends Cell Biol. 10: 429-439.

Kaffman, A., Rank, N.M., O'Neill, E.M., Huang, L.S., and O'Shea, E.K. 1998. The receptor Msn5 exports the phosphorylated transcription factor Pho4 out of the nucleus. $\mathrm{Na}$ ture 396: 482-486.

Kim, Y.J., Bjorklund, S., Li, Y., Sayre, M.H., and Kornberg, R.D. 1994. A multiprotein mediator of transcriptional activation and its interaction with the C-terminal repeat domain of RNA polymerase II. Cell 77: 599-608.

Kornitzer, D., Raboy, B., Kulka, R.G., and Fink, G.R. 1994.
Regulated degradation of the transcription factor Gen4. $E M B O$ J. 13: 6021-6030.

Liao, S.M., Zhang, J., Jeffery, D.A., Koleske, A.J., Thompson, C.M., Chao, D.M., Viljoen, M., van Vuuren, H.J., and Young, R.A. 1995. A kinase-cyclin pair in the RNA polymerase II holoenzyme. Nature 374: 193-196.

Martinez-Pastor, M.T., Marchler, G., Schuller, C., MarchlerBauer, A., Ruis, H., and Estruch, F. 1996. The Saccharomyces cerevisiae zinc finger proteins Msn2p and Msn4p are required for transcriptional induction through the stress response element (STRE). EMBO J. 15: 2227-2235.

Meimoun, A., Holtzman, T., Weissman, Z., McBride, H.J., Stillman, D.J., Fink, G.R., and Kornitzer, D. 2000. Degradation of the transcription factor Gen4 requires the kinase Pho85 and the SCF(CDC4) ubiquitin-ligase complex. Mol. Biol. Cell 11: 915-927.

Molinari, E., Gilman, M., and Natesan, S. 1999. Proteasomemediated degradation of transcriptional activators correlates with activation domain potency in vivo. EMBO J. 18: 64396447.

Myer, V.E. and Young, R.A. 1998. RNA polymerase II holoenzymes and subcomplexes. J. Biol. Chem. 273: 27757-27760.

Natarajan, K., Jackson, B.M., Zhou, H., Winston, F., and Hinnebusch, A.G. 1999. Transcriptional activation by Gen4p involves independent interactions with the SWI/SNF complex and the SRB/mediator. Mol. Cell 4: 657-664.

Niederberger, P., Miozzari, G., and Hutter, R. 1981. Biological role of the general control of amino acid biosynthesis in Saccharomyces cerevisiae. Mol. Cell Biol. 1: 584-593.

Nishizawa, M., Kawasumi, M., Fujino, M., and Toh-e, A. 1998. Phosphorylation of sic1, a cyclin-dependent kinase (Cdk) inhibitor, by Cdk including Pho85 kinase is required for its prompt degradation. Mol. Biol. Cell 9: 2393-2405.

Patton, E.E., Willems, A.R., Sa, D., Kuras, L., Thomas, D., Craig, K.L., and Tyers, M. 1998a. Cdc53 is a scaffold protein for multiple Cdc34/Skp1/F-box protein complexes that regulate cell division and methionine biosynthesis in yeast. Genes \& Dev. 12: 692-705.

Patton, E.E., Willems, A.R., and Tyers, M. 1998b. Combinatorial control in ubiquitin-dependent proteolysis: Don't Skp the F-box hypothesis. Trends Genet. 14: 236-243.

Pringle, J.R., Adams, A.E., Drubin, D.G., and Haarer, B.K. 1991. Immunofluorescence methods for yeast. Methods Enzymol. 194: 565-602.

Schmitt, A.P. and McEntee, K. 1996. Msn2p, a zinc finger DNAbinding protein, is the transcriptional activator of the multistress response in Saccharomyces cerevisiae. Proc. Natl. Acad. Sci. USA 93: 5777-5782.

Schneider, B.L., Seufert, W., Steiner, B., Yang, Q.H., and Futcher, A.B. 1995. Use of polymerase chain reaction epitope tagging for protein tagging in Saccharomyces cerevisiae. Yeast 11: 1265-1274.

Schwob, E., Bohm, T., Mendenhall, M.D., and Nasmyth, K. 1994. The B-type cyclin kinase inhibitor p40SIC1 controls the $\mathrm{G}_{1}$ to $\mathrm{S}$ transition in $S$. cerevisiae. Cell 79: 233-244.

Seol, J.H., Feldman, R.M., Zachariae, W., Shevchenko, A., Correll, C.C., Lyapina, S., Chi, Y., Galova, M., Claypool, J., Sandmeyer, S., et al. 1999. Cdc53/cullin and the essential Hrt1 RING-H2 subunit of SCF define a ubiquitin ligase module that activates the E2 enzyme Cdc34. Genes \& Dev. 13: 1614-1626.

Sherman, F. 1991. Getting started with yeast. Methods Enzymol. 194: 3-21.

Skowyra, D., Craig, K.L., Tyers, M., Elledge, S.J., and Harper, J.W. 1997. F-box proteins are receptors that recruit phos- 
Chi et al.

phorylated substrates to the SCF ubiquitin-ligase complex. Cell 91: 209-219.

Thompson, C.M., Koleske, A.J., Chao, D.M., and Young, R.A. 1993. A multisubunit complex associated with the RNA polymerase II CTD and TATA-binding protein in yeast. Cell 73: 1361-1375.

Verma, R., Annan, R.S., Huddleston, M.J., Carr, S.A., Reynard, G., and Deshaies, R.J. 1997a. Phosphorylation of Siclp by $\mathrm{G}_{1}$-CDK required for its degradation and entry into $S$ phase. Science 278: 455-460.

Verma, R., Chi, Y., and Deshaies, R.J. 1997b. Ubiquitination of cell cycle regulatory proteins in yeast extract. Methods Enzymol. 283: 366-376.

Verma, R., Feldman, R., and Deshaies, R.J. 1997c. SIC1 is ubiquitinated in vitro by a pathway that requires CDC4, CDC34, and cyclin/CDK activities. Mol. Biol. Cell 8: 1427-1437.

Zhang, X., Herring, C.J., Romano, P.R., Szczepanowska, J., Brzeska, H., Hinnebusch, A.G., and Qin, J. 1998. Identification of phosphorylation sites in proteins separated by polyacrylamide gel electrophoresis. Anal. Chem. 70: 2050-2059. 


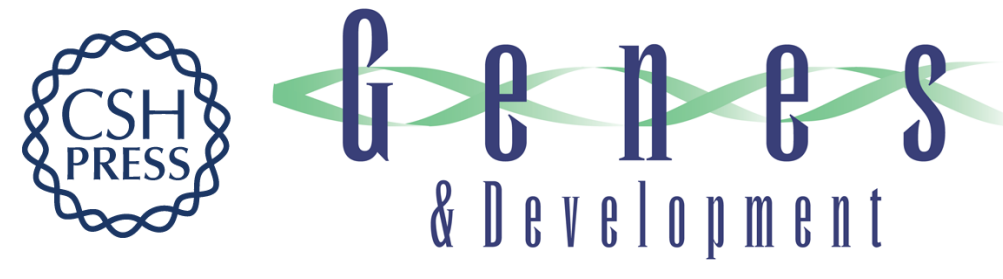

\section{Negative regulation of Gcn4 and Msn2 transcription factors by Srb10 cyclin-dependent kinase}

Yong Chi, Michael J. Huddleston, Xiaolong Zhang, et al.

Genes Dev. 2001, 15:

Access the most recent version at doi:10.1101/gad.867501

References This article cites 42 articles, 15 of which can be accessed free at: http://genesdev.cshlp.org/content/15/9/1078.full.html\#ref-list-1

License

Email Alerting Receive free email alerts when new articles cite this article - sign up in the box at the top Service right corner of the article or click here.

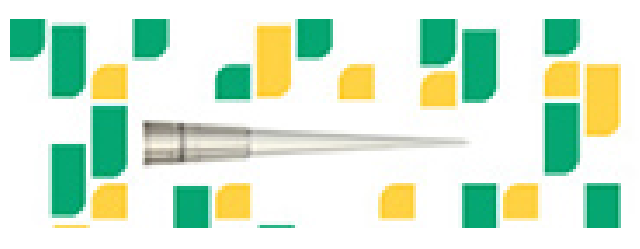

Focused on your science. 